\title{
Article \\ Novel Ensemble Tree Solution for Rockburst Prediction Using Deep Forest
}

\author{
Diyuan Li ${ }^{1, *(\mathbb{D}}$, Zida Liu ${ }^{1}$, Danial Jahed Armaghani ${ }^{2} \mathbb{D}$, Peng Xiao ${ }^{1}$ and Jian Zhou ${ }^{1} \mathbb{D}$ \\ 1 School of Resources and Safety Engineering, Central South University, Changsha 410083, China; \\ liuzida@csu.edu.cn (Z.L.); xiaopengaizhanghuimin@csu.edu.cn (P.X.); j.zhou@csu.edu.cn (J.Z.) \\ 2 Department of Urban Planning, Engineering Networks and Systems, Institute of Architecture \\ and Construction, South Ural State University, 76, Lenin Prospect, 454080 Chelyabinsk, Russia; \\ danialarmaghani@susu.ru \\ * Correspondence: diyuan.li@csu.edu.cn
}

Citation: Li, D.; Liu, Z.; Armaghani,

D.J.; Xiao, P.; Zhou, J. Novel

Ensemble Tree Solution for Rockburst

Prediction Using Deep Forest.

Mathematics 2022, 10, 787. https://

doi.org/10.3390/math10050787

Academic Editor: Manuel Pastor

Received: 9 February 2022

Accepted: 25 February 2022

Published: 1 March 2022

Publisher's Note: MDPI stays neutral with regard to jurisdictional claims in published maps and institutional affiliations.

Copyright: (c) 2022 by the authors. Licensee MDPI, Basel, Switzerland. This article is an open access article distributed under the terms and conditions of the Creative Commons Attribution (CC BY) license (https:// creativecommons.org/licenses/by/ $4.0 /)$.

\begin{abstract}
The occurrence of rockburst can cause significant disasters in underground rock engineering. It is crucial to predict and prevent rockburst in deep tunnels and mines. In this paper, the deficiencies of ensemble learning algorithms in rockburst prediction were investigated. Aiming at these shortages, a novel machine learning model, deep forest, was proposed to predict rockburst risk. The deep forest combines the characteristics of deep learning and ensemble models, which can solve complex problems. To develop the deep forest model for rockburst prediction, 329 real rockburst cases were collected to build a comprehensive database for intelligent analysis. Bayesian optimization was proposed to tune the hyperparameters of the deep forest. As a result, the deep forest model achieved $100 \%$ training accuracy and $92.4 \%$ testing accuracy, and it has more outstanding capability to forecast rockburst disasters compared to other widely used models (i.e., random forest, boosting tree models, neural network, support vector machine, etc.). The results of sensitivity analysis revealed the impact of variables on rockburst levels and the applicability of deep forest with a few input parameters. Eventually, real cases of rockburst in two gold mines, China, were used for validation purposes while the needed data sets were prepared by field observations and laboratory tests. The promoting results of the developed model during the validation phase confirm that it can be used with a high level of accuracy by practicing engineers for predicting rockburst occurrences.
\end{abstract}

Keywords: rockburst prediction; deep forest; bayesian optimization; ensemble model

MSC: 68Txx

\section{Introduction}

Rockburst is a geological catastrophe induced by the sudden release of strain energy stored in rock mass during or after the excavation of underground engineering in high in-situ stress areas. Rockburst occurs in many countries around the world [1]. It is generally believed that intensity and frequentness of rockburst increase as depth increases. The occurrence of rockburst damages underground tunnels and facilities and poses a severe threat to the safety of the operators on site. The gold mines in South Africa have greater mining depths than those in other countries. Meanwhile, most rockburst disasters occur in South African gold mines. In 1975, 73 laborers died due to 680 rockburst incidents in 31 gold mines. From 1984 to 1993, 3275 laborers lost their lives in mining geological disasters due to the lack of mining technology to cope with the rockburst below $2000 \mathrm{~m} \mathrm{[2].}$ Rockburst is a complicated problem restricting the progress of underground engineering. It is necessary for researchers to study how to prevent and control rockburst.

Many scholars have taken various measures to evaluate rockburst risk. These methods contain empirical indicators, numerical modeling, rock mechanics tests, intelligent techniques, etc. [1,3]. Xue et al. [4] adopted the empirical method to estimate the rockburst 
grade at the Jiangbian hydropower station, China. The empirical method is simple and easy to implement, but its effectiveness is poor. Zhai et al. [5] carried out rockburst tests with six hard brittle rocks subjected to one-free-face true triaxial mechanical tests. Their test results revealed that strength, fracturing, fragmentation characteristics, and failure modes had a remarkable impact on rockburst proneness. Due to scale effect considerations, experimental methods are suitable for investigating the failure process and mechanism of rockburst rather than predicting rockburst [6-8]. Moreover, the field condition is challenging to be reproduced in the laboratory. Wang et al. [9] summarized the numerical simulations, including the continuum, discontinued, and hybrid techniques for rockburst evaluation. The numerical simulation is economical, secure, and time-saving [1,3,10]. Nevertheless, choosing an appropriate constitutive model and simulation method is very important according to specific problems. With the blossom of artificial intelligence and big data, intelligent algorithms are increasingly used to predict rockbursts. Compared to empirical, numerical, and experimental methods, the intelligent model has high efficiency, good practicability and can foretell and prevent rockbursts in time. However, it requires high-quality data.

The machine learning (ML) algorithm is an essential part of the intelligent algorithm [11,12]. The ML algorithms for rockburst classification mainly include linear models (LM), decision trees (DT), artificial neural networks (ANN), $k$-nearest neighbor (KNN), Bayes classifiers, support vector machines (SVM), ensemble models, etc. Each ML model has its own supremacy and drawback, and no model can perform best for every practical engineering based on the 'No Free Lunch theorem'. Table 1 compiles the ML techniques for rockburst estimation recently and compares their advantages and disadvantages.

Table 1. The superiority and drawback of ML techniques for rockburst estimation recently.

\begin{tabular}{|c|c|c|}
\hline Algorithm & Superiority & Drawback \\
\hline $\begin{array}{l}\text { LDA [13] } \\
\text { LR [14] }\end{array}$ & $\begin{array}{l}\text { Fast training and prediction speed, and simple and easy } \\
\text { to interpret. }\end{array}$ & Unsuitable for high-dimensional data. \\
\hline $\begin{array}{l}\text { C5.0 DT [15] } \\
\text { DT [16] }\end{array}$ & $\begin{array}{l}\text { Suitable for data with missing values, and can process } \\
\text { continuous variables and discrete variables simultaneously. }\end{array}$ & $\begin{array}{l}\text { Tend to produce an overly complex model to } \\
\text { reduce its generalization. }\end{array}$ \\
\hline KNN [13] & Simple and easy to implement. & Unsuitable for unbalanced samples. \\
\hline $\begin{array}{l}\text { Naïve Bayes [13] } \\
\quad \text { BN [17] }\end{array}$ & $\begin{array}{l}\text { Simple and fast. Perform very well under the assumption } \\
\text { that distribution is independent. }\end{array}$ & $\begin{array}{l}\text { The assumption of independent distribution } \\
\text { is difficult to meet in practical projects. }\end{array}$ \\
\hline ANN [13,18-20] & $\begin{array}{l}\text { Strong mapping ability and can deal with complex } \\
\text { nonlinear problems. }\end{array}$ & $\begin{array}{l}\text { Many hyperparameters to turn and easy } \\
\text { to overfit. }\end{array}$ \\
\hline SVM $[13,21]$ & $\begin{array}{l}\text { Solid theoretical basis and can be applied to complex } \\
\text { nonlinear data. }\end{array}$ & $\begin{array}{l}\text { Difficult to deal with multiple } \\
\text { classification problems. }\end{array}$ \\
\hline $\begin{array}{c}\text { RF }[13,22] \\
\text { Bagging [23] }\end{array}$ & $\begin{array}{l}\text { Suitable for high dimension data and good } \\
\text { generalization ability. }\end{array}$ & $\begin{array}{l}\text { Overfitting appears when dealing with } \\
\text { classification with high noise. }\end{array}$ \\
\hline $\begin{array}{l}\text { GBM [13] } \\
\text { XGB [24] }\end{array}$ & $\begin{array}{l}\text { Suitable for continuous values and discrete values. Robust } \\
\text { to outliers using robust loss functions }\end{array}$ & Difficult to train data in parallel. \\
\hline
\end{tabular}

To overcome the limitations of single ML models, some researchers have combined multiple intelligent techniques to develop an ensemble model for rockburst estimation recently. Zhang et al. [25] combined seven extensively applied ML techniques using a voting strategy to construct an ensemble model, which had better performance than individual classifiers in rockburst prediction. Liang et al. [26] compared five ensemble models based on DT for forecasting short-term rockburst. They found that the RF was the optimal model. Liang et al. [27] utilized weighting voting to combine six intelligent techniques to forecast short-term rockburst. The capacity of the comprehensive combined model was better than that of the base classifiers. Yin et al. [28] used stacking to integrate KNN, SVM, deep neural networks, and recurrent neural networks for rockburst prediction. The ensemble model 
that adopted KNN and RNN performed best in all ensemble models. Although these ensemble models show a high level of prediction accuracy, some practical problems $[27,28]$ prevent them from being widely used.

(1) Ensemble models are easy to overfit. For obtaining higher prediction accuracy, ensemble models, such as RF, become complex, which makes generalization of the model poor [13].

(2) The selection of a base classifier and combination strategy is difficult [25,27-29]. Different problems require different combined strategies, there should be a difference between the base classifiers, and it is necessary to choose the combination strategy and base classifier. Otherwise, performance cannot improve.

(3) Many hyperparameters need to be tuned. The parameter setting of the ensemble model has a significant effect on the capacity.

To address the above limitations, this study proposed a novel methodology, the deep forest model, for rockburst prediction. Motivated by the theory behind deep neural networks and ensemble models, Zhou et al. [30] proposed the deep forest (DF), which combines the characteristics of deep learning models and ensemble models. DF can deal with more complex problems such as deep learning models. However, it has fewer parameters to work with than deep learning models. The DF model is easy to use, and its complexity can be determined according to the data, which can effectively prevent overfitting. The DF model is suitable for small data sets. Through validation by different data in different fields, the DF model still performs better even if it adopts the default parameter configuration. It is meaningful to build the more powerful and robust intelligent model by DF model to predict and prevent rockburst.

Additionally, Bayesian optimization (BO) is applied for optimizing hyperparameters of DF. $\mathrm{BO}$ has been widely used in hyperparametric optimization in different ML studies (e.g., [31-33]). BO differs from other optimization algorithms, and it is a useful model for problems that are expensive to conduct. $\mathrm{BO}$ constructs a probabilistic model of the objective function to be optimized and then applies the probabilistic model to determine the next point to be evaluated [34]. BO has been increasingly applied to geotechnical engineering [31,35-37].

The structure of this study is as follows: the 'Methodology' section introduces the theory and composition of DF and BO. The 'Data' section presents the source and statistical description of the rockburst database. The 'Simulation' exhibits how to construct and optimize the DF model for rockburst prediction. In the 'Discussion' section, the capability of DF to predict rockburst is evaluated. Furthermore, the influence of variables on rockburst intensities is analyzed by sensitivity analysis. Finally, the DF is applied to forecast the rockburst in practical engineering.

\section{Methodology}

\section{1. $D F$}

Zhou et al. [38] presented the gcForest to build the DF model, which consists of the cascade forest and multi-grained scanning. When the gcForest addresses sequence or image-style data, it needs multi-grained scanning. The rockburst data does not have spatial or sequential relationships in this study, so the multi-grained scanning structure in gcForest is abandoned.

$\mathrm{RF}$ and complete random forest (CRF) are the base classifiers in the DF model. The $\mathrm{RF}$ is an ensemble model composed of $K$ decision trees $\left\{h\left(X, \theta_{k}\right), k=1, \ldots, K\right\}$, where $\theta_{k}$ is a random vector that satisfies independent identically distributed [39]. Figure 1 shows flowchart to build RF. 


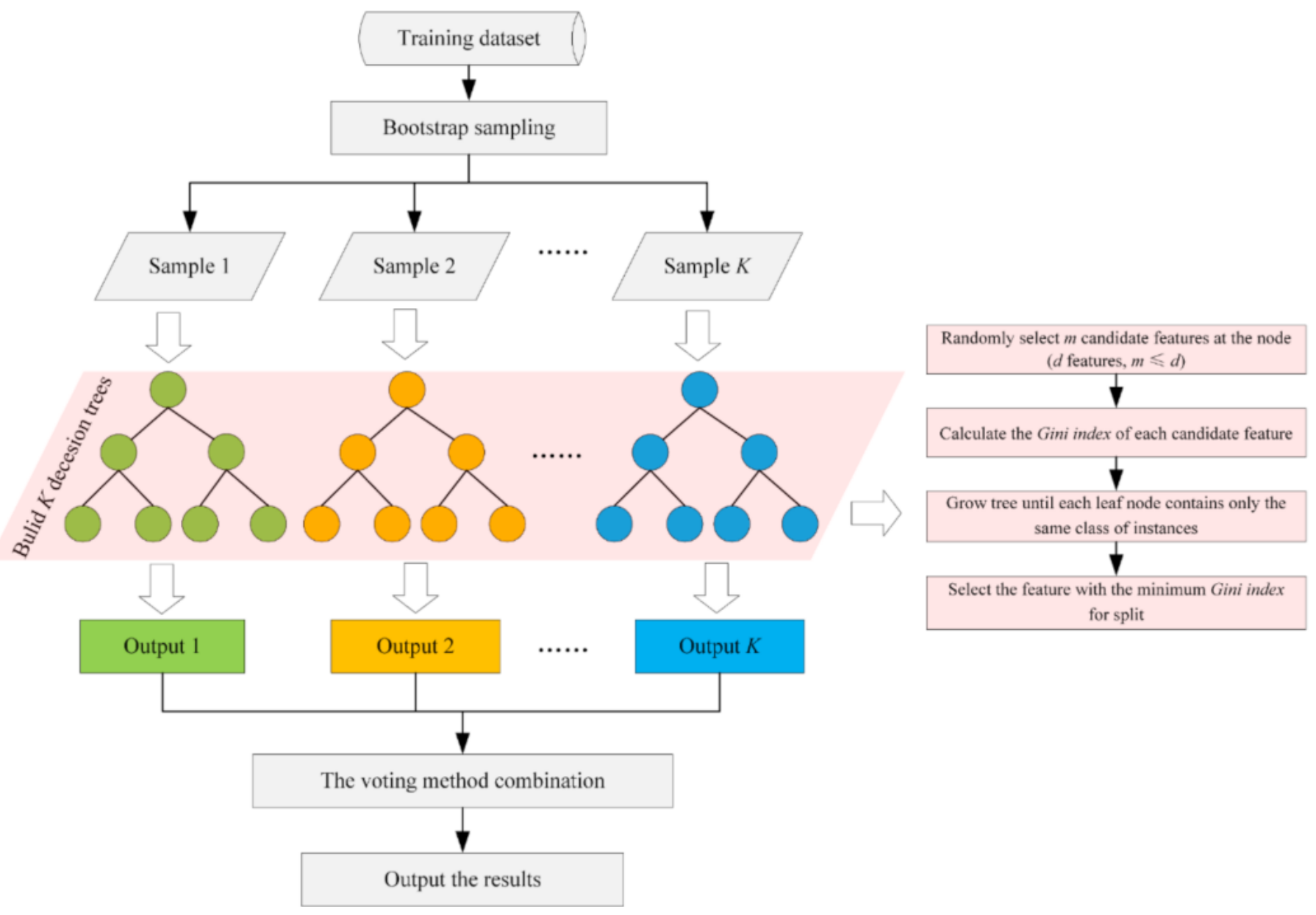

Figure 1. The flowchart to establish RF model.

Similarly, CRF randomly selects a feature for split, and the others are the same as the process of RF. As shown in Figure 2, the RF and CRF are implemented to construct cascade layers. The input features are input to the first cascade layer. After all this, the output of the previous cascade layer and the input features are input to the next layer. At this step, the training set is divided into a growing set and an estimating set. When the cascade forest increases by one layer, the estimating set tests the whole generated DF model. If the performance of the estimating set is lower than that of the previous layer, the DF model stops growing, and the cascade layer does not increase. In the last layer, the average of all the output probability vectors is calculated, and the label with the maximum probability is output as the prediction result. When the cascade layer does not increase, the DF model is retained based on the whole training set. The structure of the DF model is automatically determined, which reduces the risk of overfitting. 


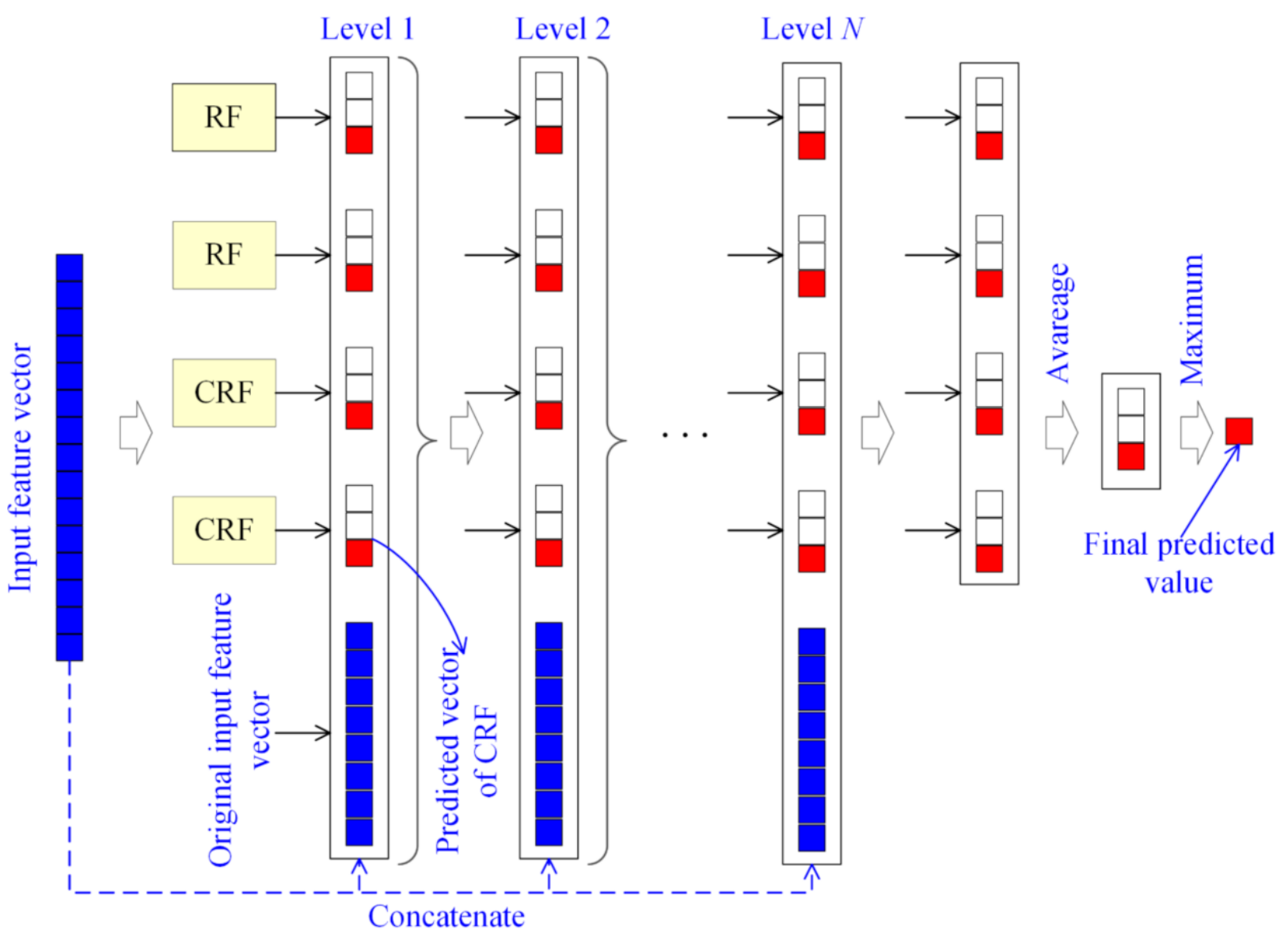

Figure 2. Schematic diagram of cascade forest.

\section{2. $B O$}

$\mathrm{BO}$ is appropriate for tasks with expensive evaluation costs [40]. BO consists of two parts, the surrogate model and the acquisition function [41]. The Gaussian process (GP) [42] is the most extensively applied surrogate model in BO due to its flexibility and tractability [40]. BO has three basic acquisition functions (AF), which are the probability of improvement [43], expected improvement [44,45], and upper/lower confidence bound. It is vital to choose an appropriate acquisition function to match the surrogate model. GPHedge is proposed to select an appropriate AF in each iteration, and detailed information about GP-Hedge can be found in previous studies [46].

\section{Data}

\subsection{Data Collection and Description}

The database, including 329 real rockburst cases worldwide, was established, as shown in Table 2. According to the criteria for the classification of rockburst in Table 3, rockburst levels can be grouped into four categories: none (53 cases), light (101 cases), moderate (119 cases), and strong (56 cases). In the collected database (Supplementary Materials), the number of light and moderate rockbursts is greater than that of none and strong rockbursts.

Rockburst often occurs on the excavation face in deep underground construction, it is induced by the sudden release of strain energy stored in the rock mass, and the most common phenomenon is strain burst. Rockburst mechanisms are complicated [47], and it is connected with stress in the earth's crust, rock property, rock mass structure, groundwater, and so on [48]. In this study, seven factors, including maximum tangential stress $\left(\sigma_{\theta}\right)$, uniaxial compressive strength $\left(\sigma_{c}\right)$, tensile strength $\left(\sigma_{t}\right)$, elastic strain energy index $\left(W_{e t}\right)$, stress concentration factor $\left(S C F\right.$ or $\left.\sigma_{\theta} / \sigma_{c}\right)$, rock brittleness index $B_{1}\left(B_{1}=\sigma_{c} / \sigma_{t}\right)$, and rock brittleness index $B_{2}\left(B_{2}=\left(\sigma_{c}-\sigma_{t}\right) /\left(\sigma_{c}+\sigma_{t}\right)\right)$, are adopted as the input variables in the DF 
model $[13,28]$. Table 4 displays the statistical description of the four rockburst intensities. Pearson correlation coefficients (Equation (1)) between variables are calculated, as shown in Figure 3. Figure 4 exhibits the boxplots and histograms of the seven input variables of four rockburst intensities. The boxplots are not symmetrical, there are many points outside the upper and lower whiskers of boxplots, and the collected database does not satisfy a normal distribution.

$$
r=\frac{\sum_{i=1}^{n}\left(X_{i}-\bar{X}\right)\left(Y_{i}-\bar{Y}\right)}{\sqrt{\sum_{i=1}^{n}\left(X_{i}-\bar{X}\right)^{2}} \sqrt{\sum_{i=1}^{n}\left(Y_{i}-\bar{Y}\right)^{2}}}
$$

Table 2. The database source.

\begin{tabular}{ccc}
\hline No. & Number of Cases & Reference \\
\hline 1 & $\mathrm{~N}$ (43 cases), L (78 cases), M (81 cases), S (44 cases) & Zhou et al. [13] \\
2 & $\mathrm{~L}$ (1 case), M (11 cases) & Pu et al. [49] \\
3 & $\mathrm{~N}$ (3 cases), L (4 cases), M (8 cases), S (1 case) & Liu et al. [50] \\
4 & $\mathrm{~N}$ (3 cases), L (7 cases), M (7 cases), S (3 cases) & Xue et al. [51] \\
5 & $\mathrm{~L}(1$ case), M (5 cases), Strong (1 case) & Wu et al. [52] \\
6 & $\mathrm{~N}(1$ case), L (2 cases), S (4 cases) & Du et al. [53] \\
7 & $\mathrm{~L}(3$ cases), M (3 cases) & Jia et al. [54] \\
8 & $\mathrm{~N}$ (3 cases), L (5 cases), M (4 cases), S (3 cases) & Xue et al. [55] \\
Sum & $\mathrm{N}$ (53 cases), L (101 cases), M (119 cases), S (56 cases) & 329 cases \\
\hline
\end{tabular}

Table 3. Standard of classification for four intensities of rockburst [48].

\begin{tabular}{cl}
\hline Rockburst Label & \multicolumn{1}{c}{ Failure Characteristics } \\
\hline None & No sound of rockburst and rockburst activities. \\
\hline Light & $\begin{array}{l}\text { The surrounding rock is spalled, cracked, or striped, and there is no } \\
\text { ejection phenomenon and a weak sound. }\end{array}$ \\
\hline Moderate & $\begin{array}{l}\text { The surrounding rock is deformed and fractured, and there is } \\
\text { aconsiderable number of rock chip ejection, loose and sudden } \\
\text { destruction, accompanied by crisp crackling, and often presented in the } \\
\text { local cavern of surrounding rock. }\end{array}$ \\
\hline Strong & $\begin{array}{l}\text { The surrounding rocks are severely bursted and suddenly thrown or shot } \\
\text { into the tunnel, accompanied by strong bursts and roaring sounds, air } \\
\text { jets, the continuity of storm phenomena, and the rapid expansion into } \\
\text { deep surrounding rocks. }\end{array}$ \\
\hline
\end{tabular}

Table 4. Statistical description of the input parameters.

\begin{tabular}{|c|c|c|c|c|c|c|c|c|}
\hline Grade & Statistical Indicators & $\sigma_{\theta}$ & $\sigma_{c}$ & $\sigma_{t}$ & $S C F$ & $B_{1}$ & $\boldsymbol{B}_{2}$ & $W_{e t}$ \\
\hline \multirow{7}{*}{ None } & Mean value & 25.27 & 101.96 & 5.98 & 0.30 & 21.08 & 0.87 & 2.78 \\
\hline & Standard deviation & 16.32 & 49.39 & 3.90 & 0.25 & 12.72 & 0.07 & 1.94 \\
\hline & Min value & 2.60 & 20.00 & 0.40 & 0.05 & 5.38 & 0.69 & 0.81 \\
\hline & 25th percentiles & 12.30 & 67.40 & 3.00 & 0.13 & 10.75 & 0.83 & 1.50 \\
\hline & 50 th percentiles & 21.50 & 96.41 & 5.00 & 0.21 & 18.75 & 0.90 & 2.04 \\
\hline & 75th percentiles & 31.20 & 123.60 & 7.60 & 0.31 & 29.40 & 0.93 & 3.60 \\
\hline & Max value & 77.69 & 241.00 & 17.66 & 1.05 & 47.93 & 1.00 & 7.80 \\
\hline
\end{tabular}


Table 4. Cont.

\begin{tabular}{|c|c|c|c|c|c|c|c|c|}
\hline Grade & Statistical Indicators & $\sigma_{\theta}$ & $\sigma_{c}$ & $\sigma_{t}$ & $S C F$ & $\boldsymbol{B}_{1}$ & $B_{2}$ & $W_{e t}$ \\
\hline \multirow{8}{*}{ Light } & Mean value & 44.42 & 116.64 & 6.68 & 0.41 & 21.53 & 0.89 & 3.72 \\
\hline & Standard deviation & 20.63 & 39.56 & 3.91 & 0.19 & 10.12 & 0.07 & 1.54 \\
\hline & Min value & 13.50 & 30.00 & 1.90 & 0.10 & 2.52 & 0.43 & 0.85 \\
\hline & 25th percentiles & 29.70 & 88.00 & 3.60 & 0.26 & 12.70 & 0.85 & 2.53 \\
\hline & 50th percentiles & 43.21 & 117.00 & 5.90 & 0.38 & 23.60 & 0.92 & 3.20 \\
\hline & 75th percentiles & 57.97 & 142.00 & 8.95 & 0.56 & 28.10 & 0.93 & 4.61 \\
\hline & Max value & 126.72 & 263.00 & 22.60 & 0.90 & 69.69 & 0.97 & 9.00 \\
\hline & Mean value & 44.42 & 116.64 & 6.68 & 0.41 & 21.53 & 0.89 & 3.72 \\
\hline \multirow{7}{*}{ Moderate } & Mean value & 51.50 & 116.58 & 6.12 & 0.47 & 25.20 & 0.90 & 5.06 \\
\hline & Standard deviation & 22.91 & 43.03 & 3.80 & 0.20 & 16.34 & 0.05 & 2.69 \\
\hline & Min value & 13.02 & 30.00 & 1.30 & 0.10 & 0.15 & 0.69 & 1.20 \\
\hline & 25 th percentiles & 37.15 & 84.30 & 2.98 & 0.34 & 15.02 & 0.87 & 3.66 \\
\hline & 50th percentiles & 51.50 & 112.50 & 5.26 & 0.47 & 21.69 & 0.91 & 5.00 \\
\hline & 75th percentiles & 65.84 & 147.53 & 8.30 & 0.59 & 27.76 & 0.93 & 5.91 \\
\hline & Max value & 118.77 & 237.20 & 17.66 & 1.27 & 80.00 & 0.98 & 21.00 \\
\hline \multirow{7}{*}{ Strong } & Mean value & 119.65 & 129.08 & 10.34 & 1.18 & 14.12 & 0.85 & 8.91 \\
\hline & Standard deviation & 83.11 & 52.37 & 4.67 & 1.17 & 5.94 & 0.06 & 6.02 \\
\hline & Min value & 16.43 & 30.00 & 2.50 & 0.10 & 5.53 & 0.69 & 2.03 \\
\hline & 25 th percentiles & 61.98 & 91.30 & 7.04 & 0.53 & 11.16 & 0.84 & 5.86 \\
\hline & 50th percentiles & 91.37 & 127.09 & 10.27 & 0.72 & 13.27 & 0.86 & 7.20 \\
\hline & 75th percentiles & 126.71 & 158.60 & 13.86 & 0.97 & 16.84 & 0.89 & 9.03 \\
\hline & Max value & 297.80 & 304.20 & 22.60 & 4.87 & 32.20 & 0.94 & 30.00 \\
\hline
\end{tabular}

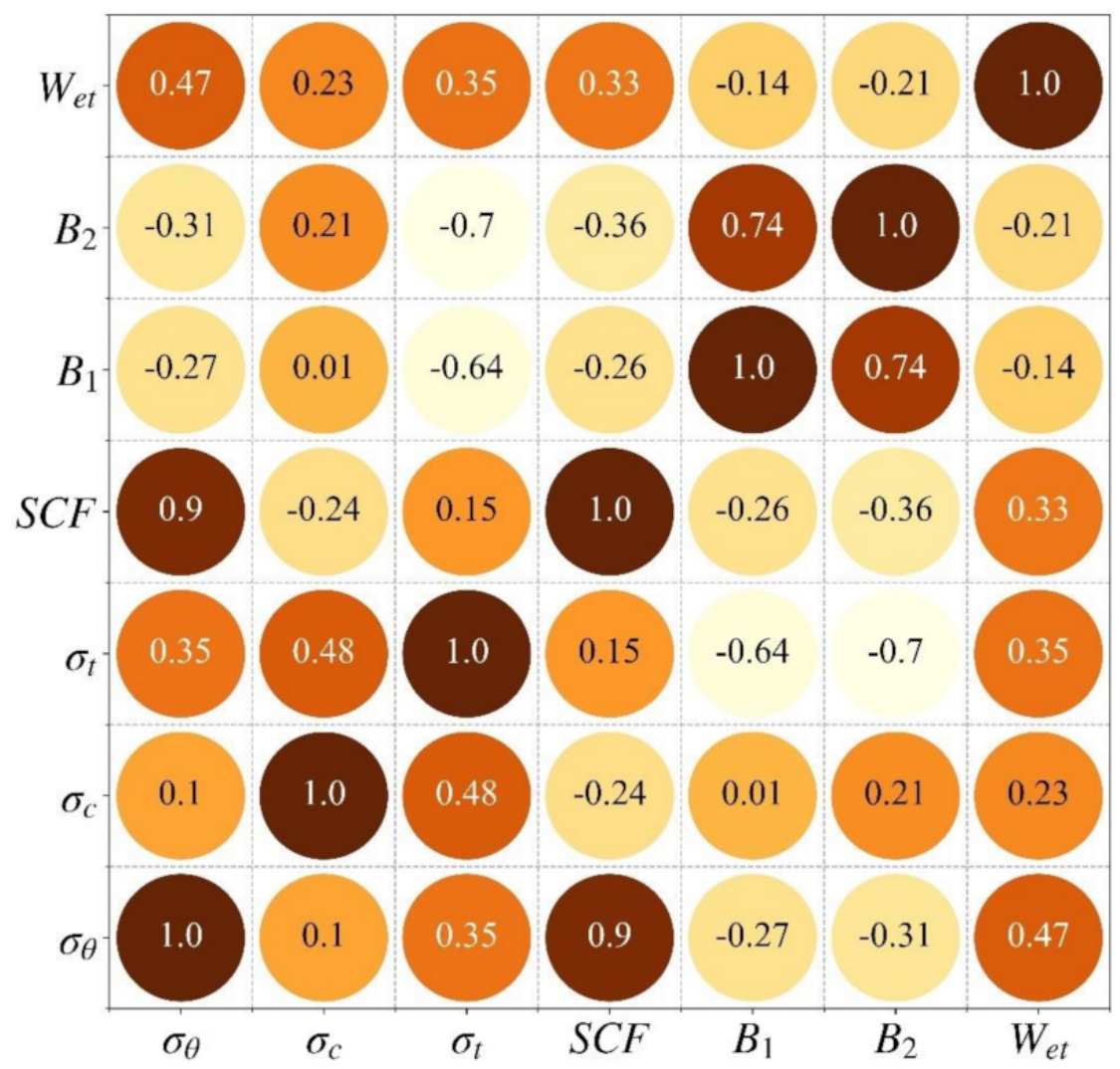

Figure 3. The heatmap of correlations between different variables. 


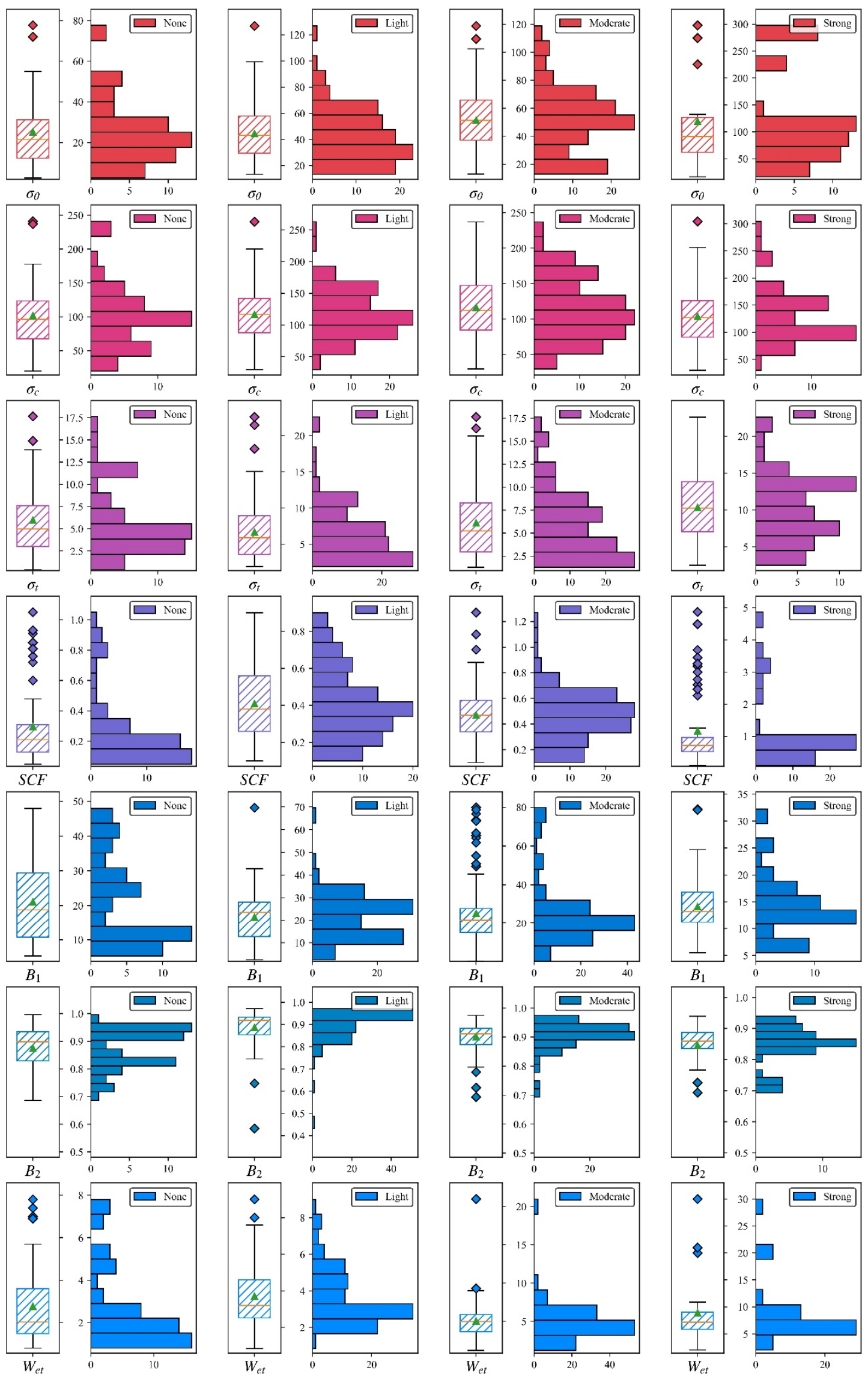

Figure 4. Boxplots and histograms of the seven variables of four rockburst intensities. 


\subsection{Step-by-Step Study Flowchart}

The database is divided into a training set (Tr) and a testing set (Te) according to three split ratios, $\operatorname{Tr}(75 \%)-\operatorname{Te}(25 \%), \operatorname{Tr}(80 \%)-\operatorname{Te}(20 \%)$, and $\operatorname{Tr}(85 \%)-\operatorname{Te}(15 \%)$. Z-score (Equation (2)) is utilized to process the input parameters. As shown in Figure 5, the training part is applied to build the DF model for rockburst estimation. BO is implemented to tune the hyperparameters of the DF. 5 fold cross-validation is implemented to choose the optimized DF model. The permutation feature importance algorithm and partial dependence plots are introduced to interpret the DF model. A sensitivity analysis is employed to analyze effective variables on rockburst intensities and the robustness of the DF model. Finally, the intelligent model is applied to foretell rockburst in practical engineering.

$$
X^{\prime}=\frac{X-\bar{X}}{\sigma}
$$

In Equation (2), $\bar{X}$ depicts the average value and $\sigma$ represents the standard deviation.

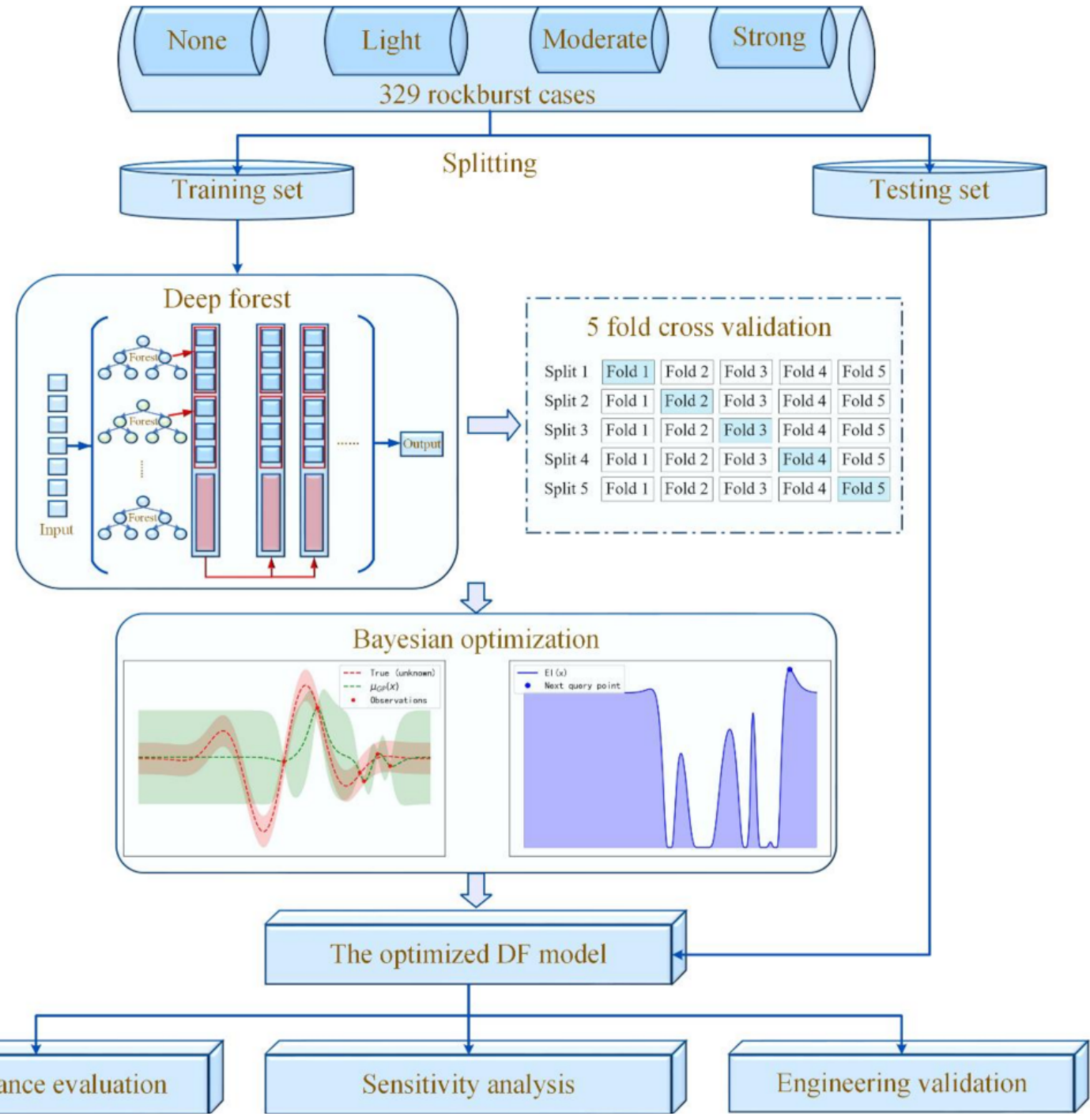

Figure 5. The flowchart to develop DF model for rockburst prediction.

\section{Simulation}

\subsection{Model Metrics}

Accuracy is often used as the metric index in the ML classification problem. Equation (3) shows the equation to calculate accuracy. According to the actual label and the predicted 
label, the sample can be divided into true positives (TP), false positives (FP), true negatives (TN), and false negatives (FN). The sum of the samples $=\mathrm{TP}+\mathrm{FP}+\mathrm{TN}+\mathrm{FN}$. According to these, the precision and recall can be calculated, as shown in Equations (4) and (5). In precision and recall, usually, when one is higher, the other is lower. In order to integrate precision and recall, their harmonically average value, i.e., $f_{1}$, is usually taken (Equation (6)). Additionally, a receiver operating characteristic (ROC) curve is introduced to evaluate the capability of single rockburst types. The area under the ROC curve is between 0 and 1. A larger area of the ROC curve indicates a better prediction effect of the model.

$$
\begin{gathered}
\text { Accuracy }=\frac{n^{\prime}}{n} \\
\text { precision }=\frac{T P}{T P+F P} \\
\text { recall }=\frac{T P}{T P+F N} \\
f_{1}=\frac{2 \times \text { precision } \times \text { recall }}{\text { precision }+ \text { recall }}
\end{gathered}
$$

In Equation (3), $n$ represents the number of all datasets, and $n^{\prime}$ stands for the number of instances of which the predicted labels are equal to actual labels.

\subsection{Cross-Validation}

When the hyperparameters of ML models are optimized, the generalization of the model needs to be evaluated to select the optimal model. $K$ fold cross-validation is often adopted in model evaluation. In cross-validation, $k$ is usually set to 10 or 5 [56]. In this study, $k$ was set to 5 by referring to a previous study [25] to reduce the running time. As shown in Figure 6, the training set is divided into five pieces of data equal to each other,

\begin{tabular}{|c|c|c|c|c|c|c|c|c|}
\hline & Test & \multicolumn{4}{|c|}{ Training } & & & \\
\hline Split 1 & Fold 1 & Fold 2 & Fold 3 & Fold 4 & Fold 5 & Fold 1 & Score $_{1}$ & \\
\hline Split 2 & Fold 1 & Fold 2 & Fold 3 & Fold 4 & Fold 5 & Fold 2 & Score $_{2}$ & \\
\hline Split 3 & Fold 1 & Fold 2 & Fold 3 & Fold 4 & Fold 5 & Fold 3 & Score $_{3}$ & Score $=\frac{1}{5} \sum$ Score \\
\hline Split 4 & Fold 1 & Fold 2 & Fold 3 & Fold 4 & Fold 5 & Fold 4 & Score $_{4}$ & \\
\hline Split 5 & Fold 1 & Fold 2 & Fold 3 & Fold 4 & Fold 5 & Fold 5 & Score $_{5}$ & \\
\hline
\end{tabular}
four pieces of data are selected to train each time, and the remaining piece of data is used for validation. The process is repeated five times, and finally, the average value of the five validation scores is taken.

Figure 6. The steps to perform 5 fold CV.

\subsection{DF Optimization}

$\sigma_{\theta}, \sigma_{c}, \sigma_{t}, S C F, B_{1}, B_{2}$, and $W_{e t}$ were input to the DF to develop a rockburst prediction model. The cascade layers in the DF can be automatically determined according to the training set. The number of forests, the trees in each forest, and the maximum number of cascade layers are the key parameters that influence the performance of DF. Referring to previous studies by Zhou et al. [30], the optimization range of these hyperparameters was determined, as shown in Table 5.

Table 5. The optimization range of hyperparameters in the DF model.

\begin{tabular}{cc} 
Hyperparameters & Optimization Range \\
\hline The number of forests & $(1,4)$ \\
The trees in the forest & $(10,100)$ \\
The maximum number of cascade layers & $(10,30)$ \\
\hline
\end{tabular}


BO was implemented to optimize the hyperparameters of the DF to choose an optimal model. Before performing BO, the objective function needed to be defined, and BO was utilized to optimize this objective function. The cross-entropy loss function is commonly used for classification problems in ML areas, as shown in Equation (7). The smaller the value is, the better the capability of the model. To improve the generalization of the DF model, the cross-entropy loss function in 5 fold cross-validation was chosen as the objective function, as shown in Equation (8).

$$
\begin{gathered}
\text { loss }=-\frac{1}{n} \sum_{i=1}^{n} \log p_{\operatorname{model}}\left[y_{i} \in C_{y_{i}}\right] \\
\text { Objective_function }=\frac{1}{5} \sum_{1}^{5} \operatorname{loss}_{i}
\end{gathered}
$$

In Equation (7), $p_{\text {model }}\left[y_{i} \in C_{y_{i}}\right]$ is the prediction probability in the actual label. Equation (8) means that the training set is split into five folds, four folds are applied to train the DF model, and the cross-entropy loss function of the DF on the remaining one fold is calculated. Repeating the process five times, the average value of the cross-entropy loss function is chosen as the objective function.

BO was performed using Scikit-Optimize, an open-source Python library [57]. The parameters of BO utilized the default value of Scikit-Optimize. Table 6 lists the values of hyperparameters in BO in this study. Gaussian process was chosen as the surrogate model, and GP-Hedge was selected as the acquisition function. Figure 7 exhibits the flowchart in which BO tunes the hyperparameters of the DF model. In the BO process, GP-Hedge determines the following points that need to be evaluated. The DF model trains according to the hyperparameter value recommended by the GP-Hedge. After the DF is built, the objective function is calculated, and the GP model is updated. By repeating this process $N$ times, the optimal hyperparameters can be obtained. Figure 8 exhibits the convergence of the objective function with the process of BO. BO can efficiently minimize the objective function to find the optimal DF model. Table 7 shows the optimal hyperparameters of the DF model with different training sets at the end of BO.

Table 6. The parameters of $\mathrm{BO}$.

\begin{tabular}{cll}
\hline Surrogate Model & Acquisition Function & \multicolumn{1}{c}{ Surrogate Model Hyperparameters } \\
\hline \multirow{3}{*}{ GP } & GP-Hedge & 1. Kernel function: Matern Kernel and \\
& & White Kernel \\
& & 2. Noise: Gaussian distribution \\
\hline
\end{tabular}

Table 7. The optimal hyperparameters in the DF model.

\begin{tabular}{ccc}
\hline Datasets & Hyperparameters & Value \\
\hline $\operatorname{Tr}(75 \%)-\operatorname{Te}(25 \%)$ & The number of forests & 4 \\
& The trees in the forest & 36 \\
& The maximum number of cascade layers & 30 \\
\hline $\operatorname{Tr}(80 \%)-\operatorname{Te}(20 \%)$ & The number of forests & 4 \\
& The trees in the forest & 18 \\
& The maximum number of cascade layers & 19 \\
\hline $\operatorname{Tr}(85 \%)-\operatorname{Te}(15 \%)$ & The number of forests & 4 \\
& The trees in the forest & 25 \\
& The maximum number of cascade layers & 25 \\
\hline
\end{tabular}




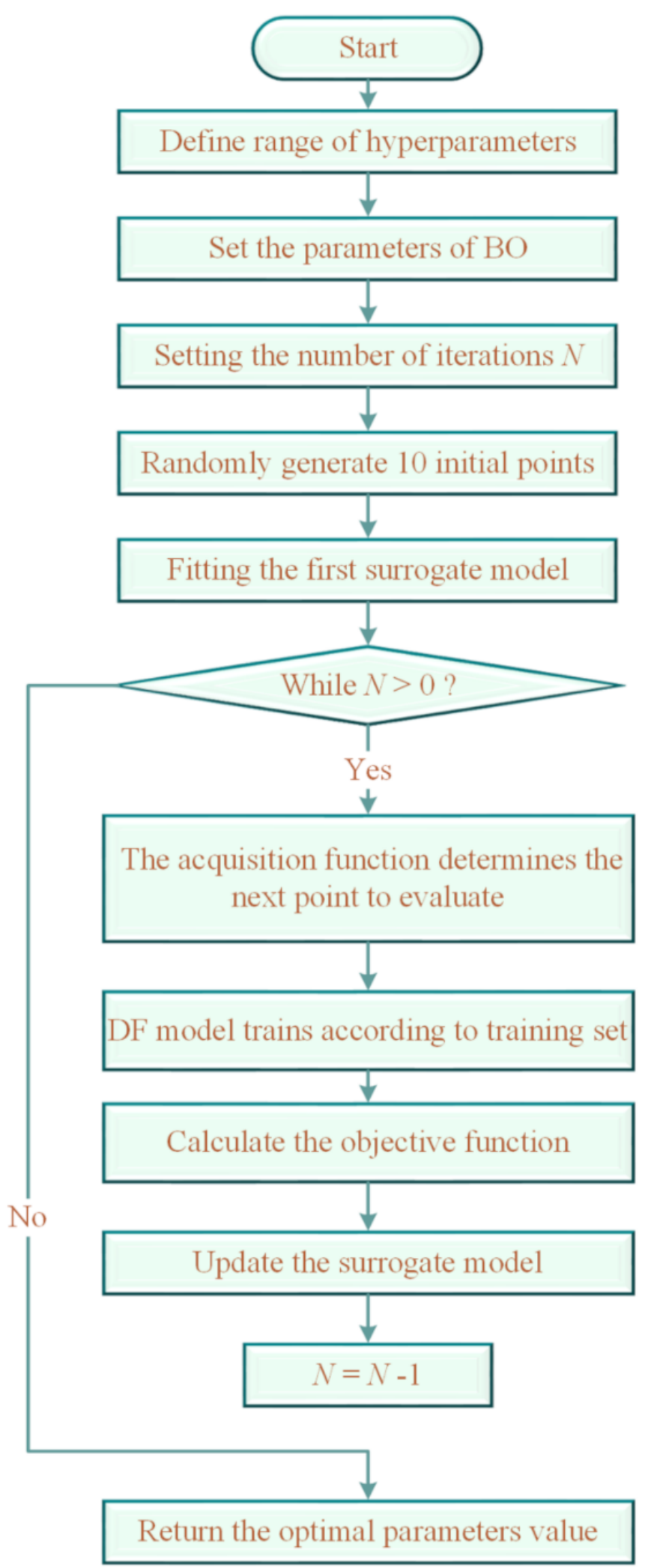

Figure 7. The flowchart of BO. 


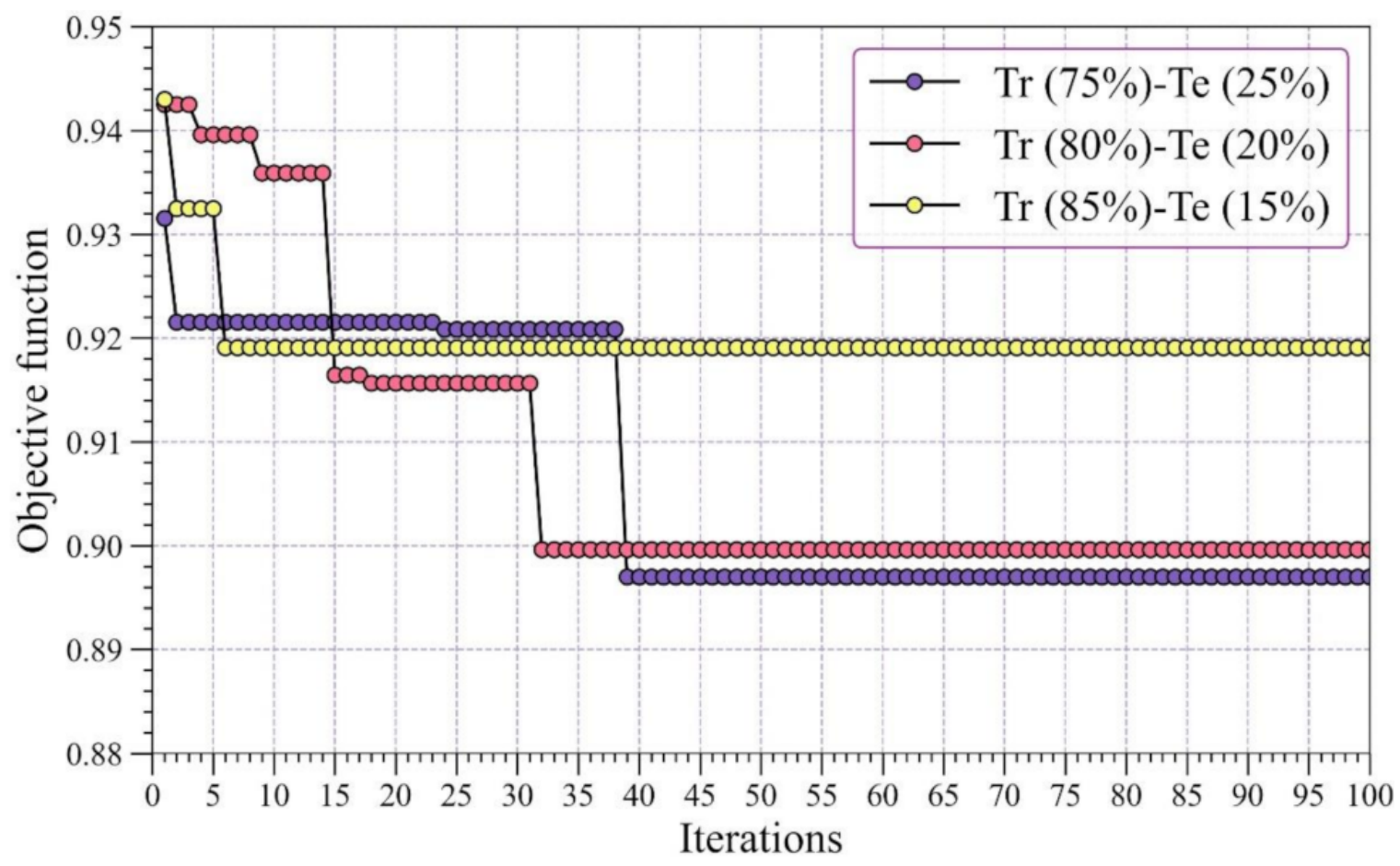

Figure 8. Convergence of objective function during BO.

\subsection{Results}

The optimized DF models with different training sets were obtained according to Table 7, and in three different training sets, the training accuracies of DF models were $100 \%$. The remaining three testing sets were adopted to evaluate the capability of DF models. Tables 8-10 present the performances of DF models on the different testing sets. The three DF models developed by different training datasets had the same capabilities in predicting strong rockburst. In terms of testing accuracy, the DF model with $\operatorname{Tr}(80 \%)-\operatorname{Te}(20 \%)$ has the best capacity. Accordingly, it is appropriate to develop DF models to predict rockburst by $80 \%$ training set and $20 \%$ testing set.

Table 8. The testing performance of DF models with $\operatorname{Tr}(75 \%)-\mathrm{Te}(25 \%)$.

\begin{tabular}{ccccc}
\hline Rockburst Type & Precision & Recall & $f_{1}$ & Number \\
\hline None & 0.86 & 0.92 & 0.89 & 13 \\
Light & 0.95 & 0.76 & 0.84 & 25 \\
Moderate & 0.88 & 1.00 & 0.94 & 30 \\
Strong & 1.00 & 1.00 & 1.00 & 14 \\
Accuracy & & $91.5 \%$ & & 82 \\
\hline
\end{tabular}

Table 9. The testing performance of DF models with $\operatorname{Tr}(80 \%)-\mathrm{Te}(20 \%)$.

\begin{tabular}{ccccc}
\hline Rockburst Type & Precision & Recall & $f_{1}$ & Number \\
\hline None & 0.91 & 0.91 & 0.91 & 11 \\
Light & 0.94 & 0.80 & 0.86 & 20 \\
Moderate & 0.89 & 1.00 & 0.94 & 24 \\
Strong & 1.00 & 1.00 & 1.00 & 11 \\
Accuracy & & $92.4 \%$ & & 66 \\
\hline
\end{tabular}


Table 10. The testing performance of DF models with $\operatorname{Tr}(85 \%)-\mathrm{Te}(15 \%)$.

\begin{tabular}{ccccc}
\hline Rockburst Type & Precision & Recall & $f_{1}$ & Number \\
\hline None & 1.00 & 0.88 & 0.93 & 8 \\
Light & 0.92 & 0.80 & 0.86 & 15 \\
Moderate & 0.86 & 1.00 & 0.92 & 18 \\
Strong & 1.00 & 1.00 & 1.00 & 8 \\
Accuracy & & $91.8 \%$ & & 49 \\
\hline
\end{tabular}

\section{Discussion}

\subsection{Model Performance Comparison}

DF model consists of RF and CRF, and to analyze the advantages of DF compared to its base classifiers, RF and CRF are also independently built with the same hyperparameters $(\operatorname{Tr}(80 \%)-\mathrm{Te}(20 \%))$ in Table 7 . The training accuracy in RF and CRF was $100 \%$ and 99.6\%, respectively, and Tables 11 and 12 display the testing performance of RF and CRF, respectively. According to Table 9, the DF has higher testing accuracy than RF and CRF, which reveals that model combination can improve the capability for predicting rockburst. The ROC curve is introduced to compare the performance of each rockburst intensity in DF, $R F$, and CRF. Figure 9 exhibits the ROC curves of the four rockburst intensities in DF, RF, and CRF. The larger area of the ROC curve is associated with better model performance. DF, $\mathrm{RF}$, and CRF perform similarly in terms of strong rockburst prediction, but DF outperforms $\mathrm{RF}$ and CRF in terms of none, light, and moderate rockburst prediction.

Table 11. The testing performance of the RF model.

\begin{tabular}{ccccc}
\hline Rockburst Type & Precision & Recall & $f_{1}$ & Number \\
\hline None & 0.75 & 0.82 & 0.78 & 11 \\
Light & 0.74 & 0.85 & 0.79 & 20 \\
Moderate & 0.95 & 0.83 & 0.89 & 24 \\
Strong & 1.00 & 0.91 & 0.95 & 11 \\
Accuracy & & $84.8 \%$ & & 66 \\
\hline
\end{tabular}

Table 12. The testing performance of the CRF model.

\begin{tabular}{ccccc}
\hline Rockburst Type & Precision & Recall & $f_{1}$ & Number \\
\hline None & 0.75 & 0.82 & 0.78 & 11 \\
Light & 0.75 & 0.75 & 0.75 & 20 \\
Moderate & 0.84 & 0.88 & 0.86 & 24 \\
Strong & 1.00 & 0.82 & 0.90 & 11 \\
Accuracy & & $81.8 \%$ & & 66 \\
\hline
\end{tabular}

Additionally, to explore the power of the DF model, widely used ML models were also developed in this study, and they included LR, Naive Bayes, KNN, SVM, DT, adaptive boosting (AdaBoost), ANN, XGB, and GBM. XGB was built using the default parameters in XGBoost (a Python library) [51], and other models used the Scikit-learn [52] default parameters. Training set $(80 \%)$ was applied to develop these models, and testing set $(20 \%)$ was adopted to evaluate these models. Figure 10 displays the training and testing accuracy of these models. The DT suffers from serious overfitting, and its performance differs markedly between the training and testing sets. Many ensemble tree models, i.e., GBM, XGB, and RF, perform better than other ML models. Taylor diagrams [58,59] were introduced to determine the strength of the DF model compared to other models. In this study, Taylor diagrams combine the Matthews correlation coefficient (MCC), centered root mean square error (green dotted lines in Figure 11), and standard deviation into a polar diagram. Equation (9) shows the equation to calculate MCC. The reference points with black star shapes depict the actual rockburst, and when other points are closer to 
the reference points, the corresponding models have better performance in predicting rockburst. It is worth noting that the DF model outperforms other commonly used tree models in the training and testing sets, according to Figure 11.
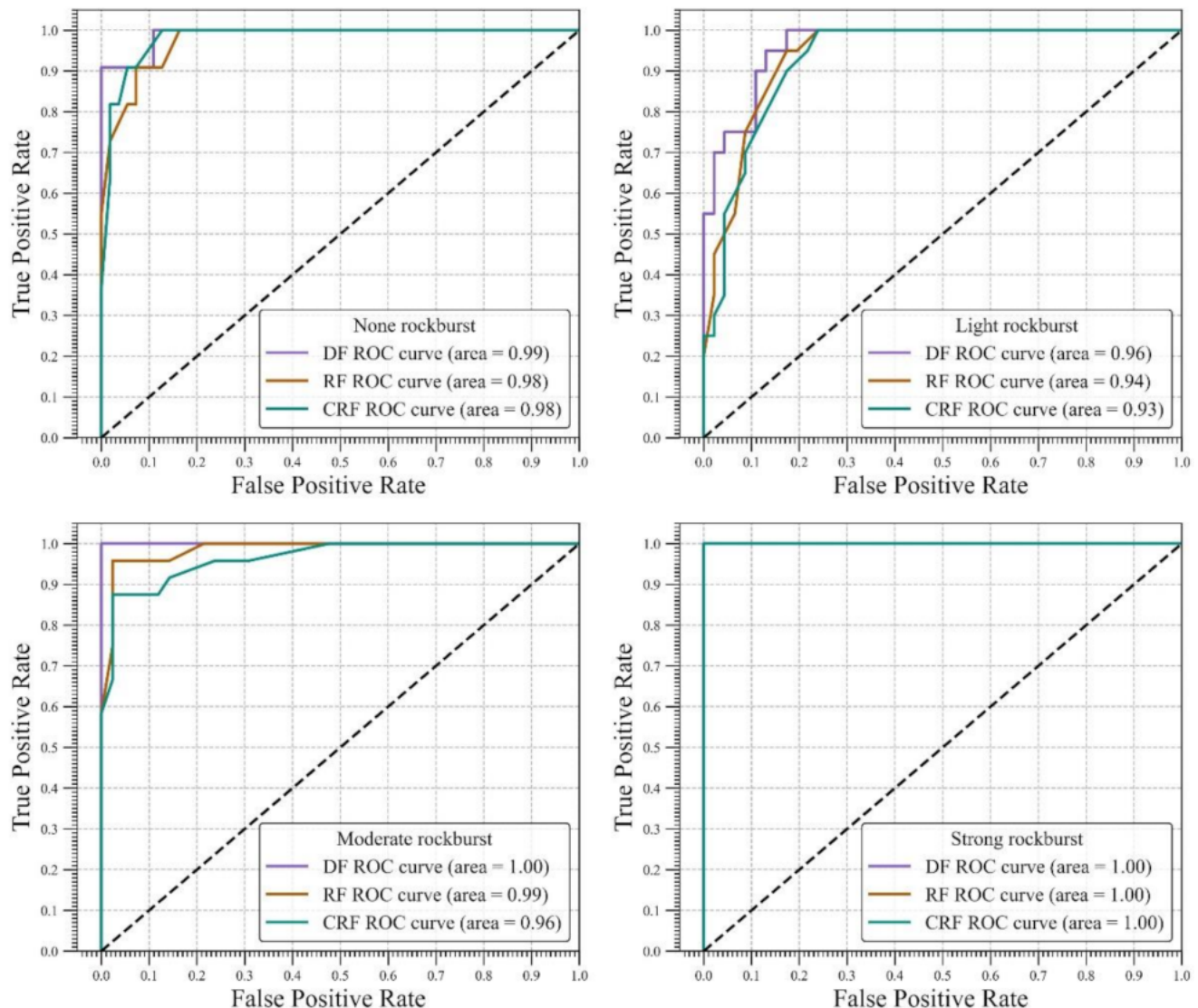

Figure 9. Model performance comparison in each rockburst by ROC curve.

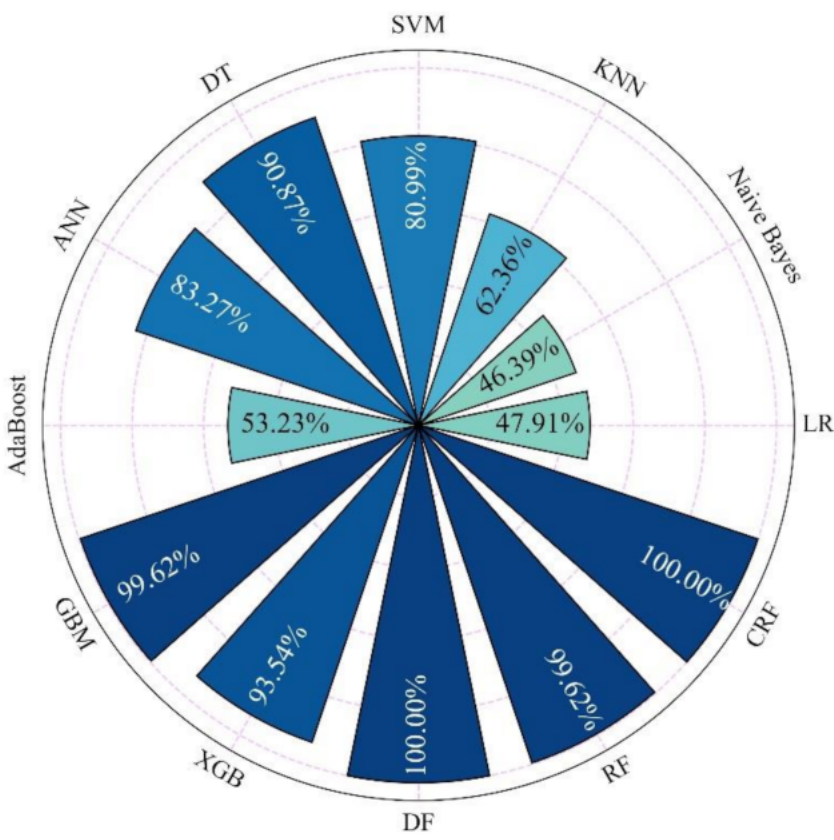

(a)

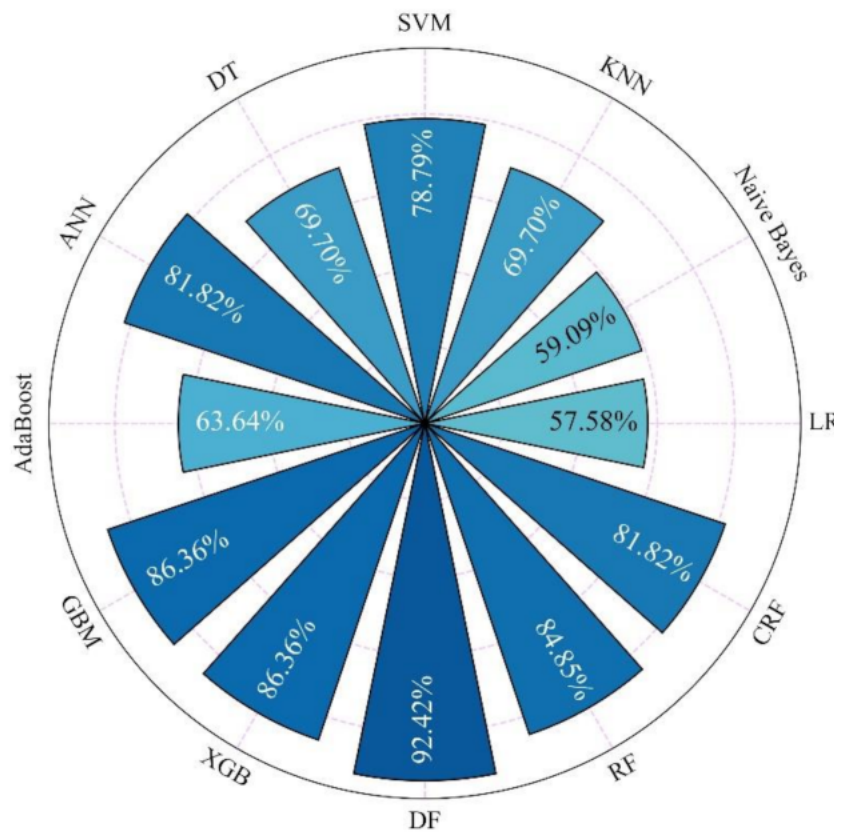

(b)

Figure 10. Training and testing results of the developed models. (a) Training accuracy; (b) Testing accuracy. 


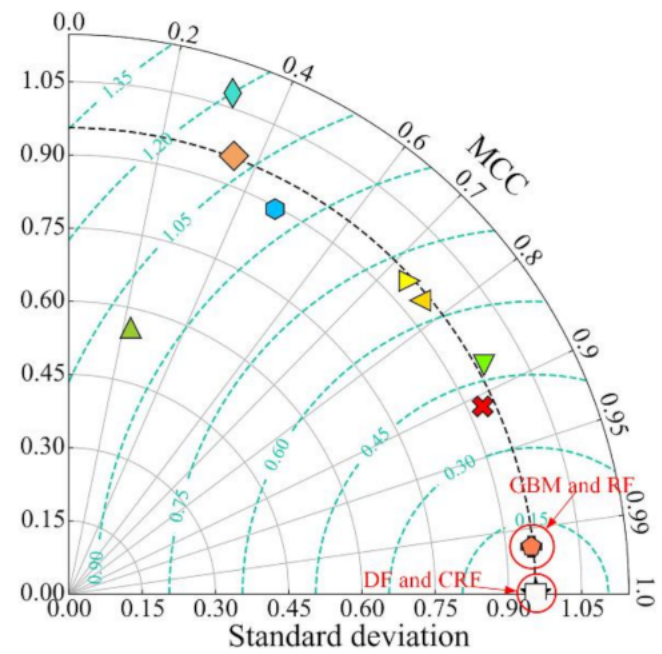

(a)

\begin{tabular}{|c|c|}
\hline$\square$ & DF \\
\hline & CRF \\
\hline & RF \\
\hline & XGB \\
\hline & GBM \\
\hline & AdaBoost \\
\hline$<$ & ANN \\
\hline$D$ & SVM \\
\hline$\triangle$ & NB \\
\hline & DT \\
\hline & LR \\
\hline & KNN \\
\hline
\end{tabular}

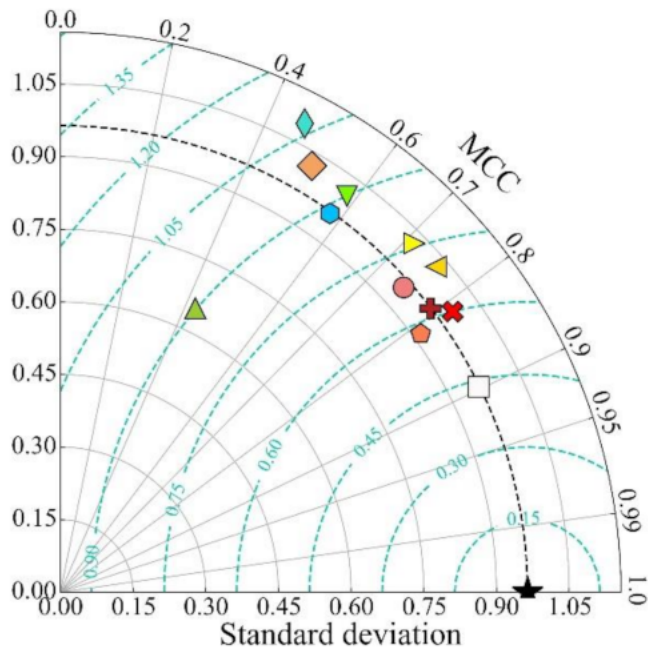

(b)

Figure 11. Taylor diagrams for comparing the performance of developed models. (a) Training results; (b) Testing results.

Additionally, Table 13 compares the capabilities of DF and some intelligent models proposed by other scholars in recent years, and the DF model has better performance than other models during training and testing phases. The results reveal that the DF model is a powerful technique to forecast and prevent rockburst.

$$
M C C=\frac{T P \times T N-F P \times F N}{\sqrt{(T P+F P)(T P+F N)(T N+F P)(T N+F N)}}
$$

Table 13. Comparison of DF and other ML models proposed in recent years.

\begin{tabular}{ccccc}
\hline \multirow{2}{*}{ Algorithm/Model } & Input Parameters & Data Size & \multicolumn{2}{c}{ Accuracy } \\
\cline { 3 - 5 } & & & Training & Testing \\
\hline Voting model [25] & $H, \sigma_{\theta}, \sigma_{c}, \sigma_{t}, W_{e t}$ & 188 & $94 \%$ & $80 \%$ \\
PSO-ELM [55] & $\sigma_{\theta}, \sigma_{c}, \sigma_{t}, S C F, B_{1}, W_{e t}$ & 344 & $98.99 \%$ & $88.89 \%$ \\
Bagging [23] & $\sigma_{\theta}, \sigma_{c}, \sigma_{t}, S C F, B_{1}, W_{e t}$ & 102 & $100 \%$ & $88.24 \%$ \\
Boosting [23] & $\sigma_{\theta}, \sigma_{c}, \sigma_{t}, S C F, B_{1}, W_{e t}$ & 102 & $100 \%$ & $91.18 \%$ \\
Stacking model [28] & $\sigma_{\theta}, \sigma_{c}, \sigma_{t}, S C F, B_{1}, B_{2}, W_{e t}$ & 246 & & $88.52 \%$ \\
DF & $\sigma_{\theta}, \sigma_{c}, \sigma_{t}, S C F, B_{1}, B_{2}, W_{e t}$ & 329 & $100 \%$ & $92.40 \%$ \\
\hline
\end{tabular}

Note: Voting model is the combination of back propagation neural network, KNN, SVM, LR, linear model, DT, and Naive Bayes; $H=$ depth; POS = particle swarm optimization; ELM = extreme learning machine; stacking model is the combination of KNN, SVM, deep neural network, and recurrent neural network.

\subsection{Sensitivity Analysis}

The permutation feature importance was implemented to determine crucial variables that affected rockburst in the DF model. The permutation feature importance was beneficial for analyzing the relative importance of input variables in nonlinear or opaque ML models [60], and it is introduced to determine the importance score of input parameters. Figure 12 shows the importance score of the input parameters in the DF model. According to this Figure $12, \sigma_{\theta}, W_{\text {et }}$, and SCF are the vital parameters that influence the performance of rockburst prediction. 


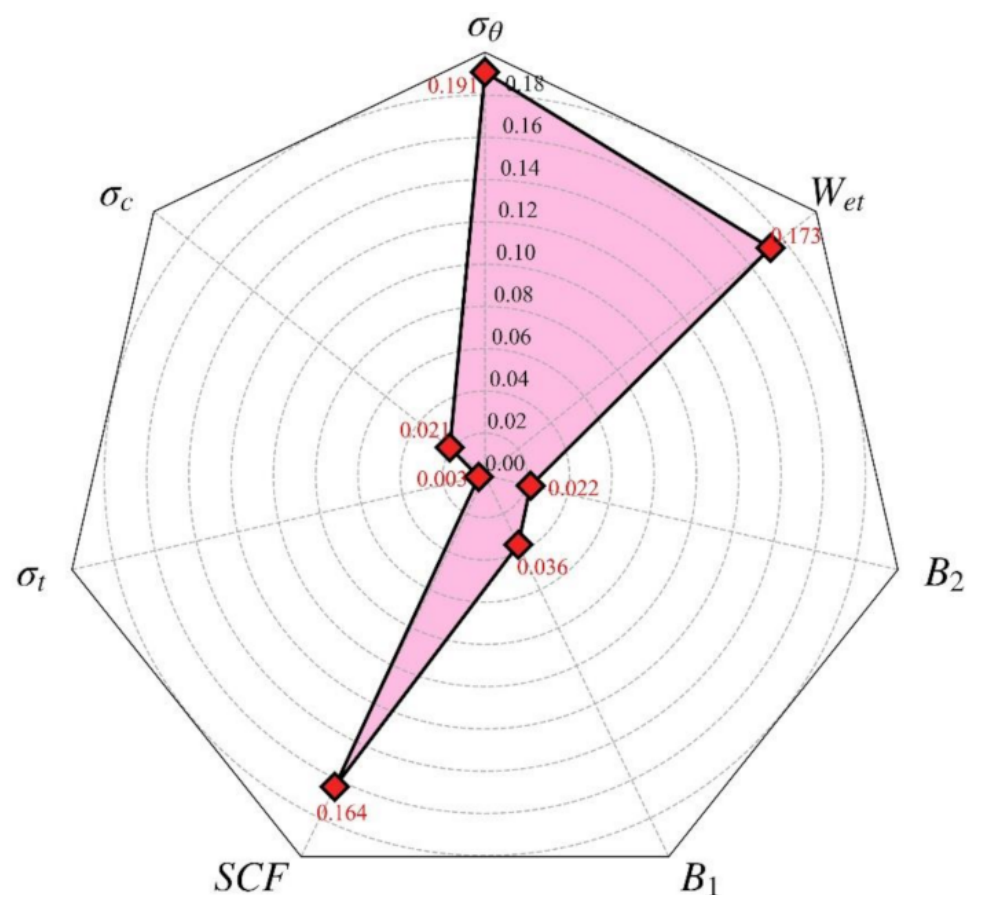

Figure 12. The relative importance of input variables in the DF model.

To determine the impact of parameters on the rockburst levels, partial dependence plots (PDP) [61] were introduced to analyze the relationship between variables and predicted results of the DF model, as shown in Figure 13. The PDP displays the dependence of the predicted probability of different rockburst levels on the variable of interest when other variables are fixed. With the increase of $\sigma_{\theta}, W_{e t}$, and $S C F$, the predicted probability of a strong rockburst increases, and the predicted probability of a none rockburst decreases. There is no apparent relationship between the other variables and the predicted probability of rockburst in the DF model. These results indicate that larger $\sigma_{\theta}, W_{e t}$, and $S C F$ values are accompanied by more serious rockburst. Accordingly, it is vital to reduce the $\sigma_{\theta}, W_{e t}$, and $S C F$ of surrounding rock in underground engineering to mitigate the rockburst risk. Some measures, such as smooth blasting, pressure relief blasting, and deformable bolts and mesh, can be applied to prevent rockburst on-site [62].

The key parameters affecting rockburst intensities are determined, which makes it possible to analyze the performance variation of the DF model under different influential variables. According to the relative importance of the input variables, seven models that adopted different input parameters were developed, as shown in Table 14. These seven models adopted the same hyperparameters $(\operatorname{Tr}(80 \%)$-Te $(20 \%))$ in Table 7 . Figure 14 displays the variations of training and testing accuracy with the input variable number varying. With the decrease of input parameters, DF has low accuracy, which suggests that considering more factors is beneficial to improving the generalization of DF and predicting and preventing rockburst due to the complexity of rockburst. Additionally, with only three input parameters, the testing accuracy of the DF model is still $81.82 \%$, which indicates that the DF model has good robustness and is suitable for fewer input parameters. 


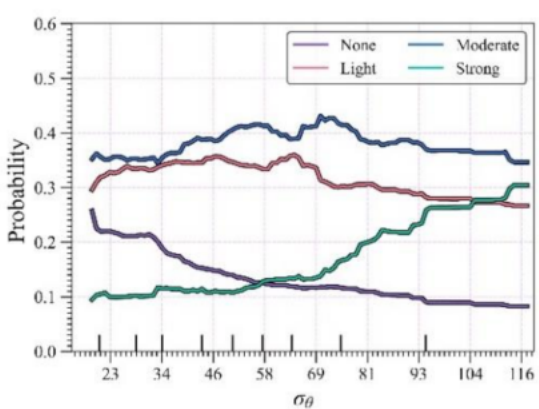

(a)

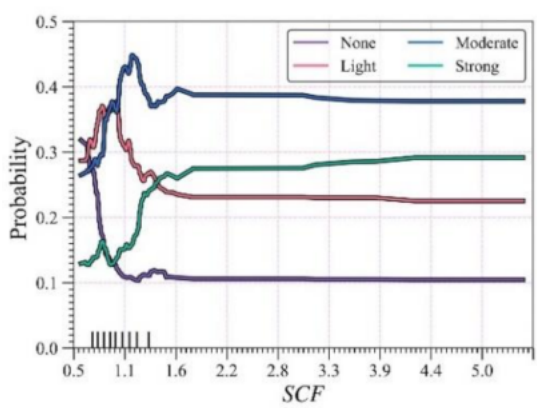

(d)

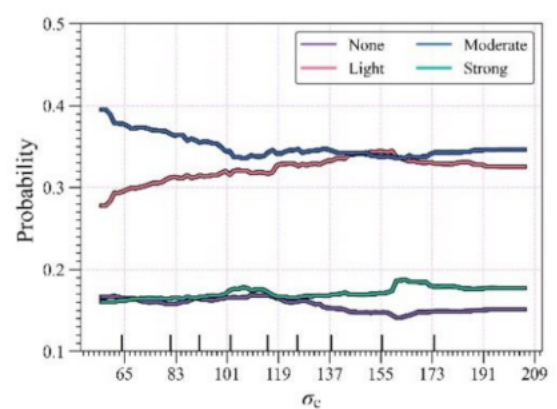

(b)

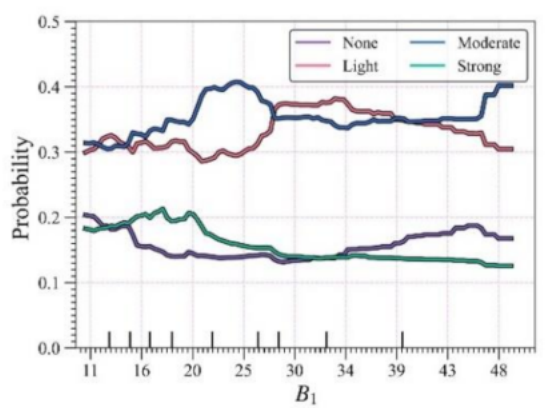

(e)

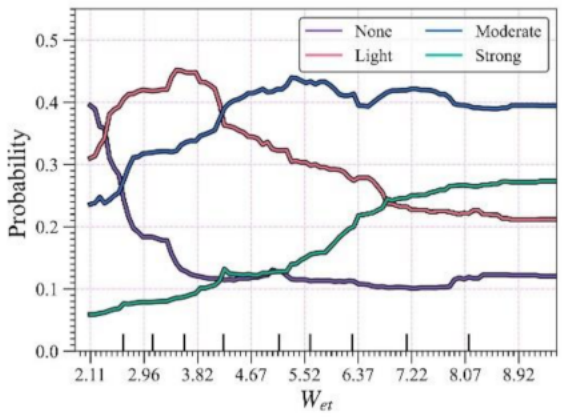

(g)

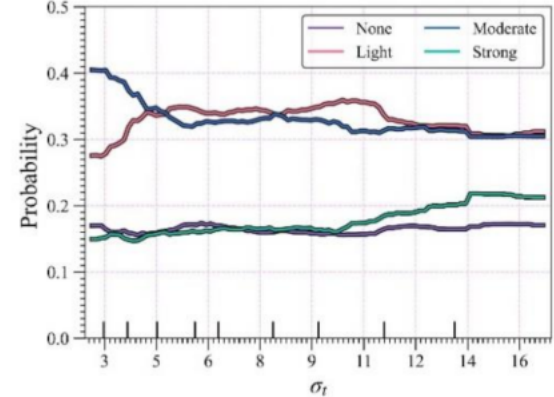

(c)

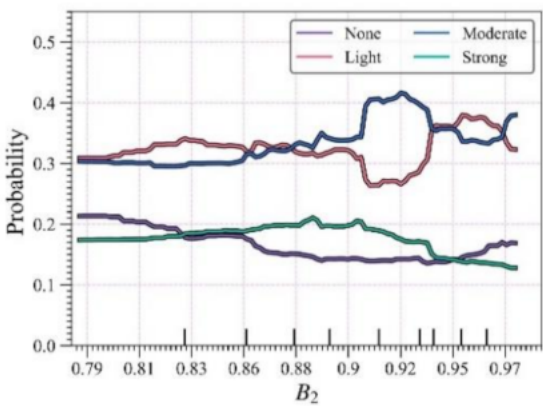

(f)

igure 13. PDP to analyze the influence of variables on the rockburst predicted probability. (a) $\sigma_{\theta}$ (b) $\sigma_{\mathrm{c}} ;$ (c) $\sigma_{t} ;$ (d) $S C F ;(\mathbf{e}) B_{1} ;$ (f) $B_{2} ;(\mathbf{g}) W_{e t}$.

Table 14. Seven models and their input parameters.

\begin{tabular}{ccc}
\hline Model & Input Parameters & Input Parameters Number \\
\hline M 1 & $\sigma_{\theta}, \sigma_{c}, \sigma_{t}, S C F, B_{1}, B_{2}, W_{e t}$ & 7 \\
M 2 & $\sigma_{\theta}, \sigma_{c}, S C F, B_{1}, B_{2}, W_{e t}$ & 6 \\
M 3 & $\sigma_{\theta}, S C F, B_{1}, B_{2}, W_{e t}$ & 5 \\
M 4 & $\sigma_{\theta}, S C F, B_{1}, W_{e t}$ & 4 \\
M 5 & $\sigma_{\theta}, S C F, W_{e t}$ & 3 \\
M 6 & $\sigma_{\theta}, W_{e t}$ & 2 \\
M 7 & $\sigma_{\theta}$ & 1 \\
\hline
\end{tabular}




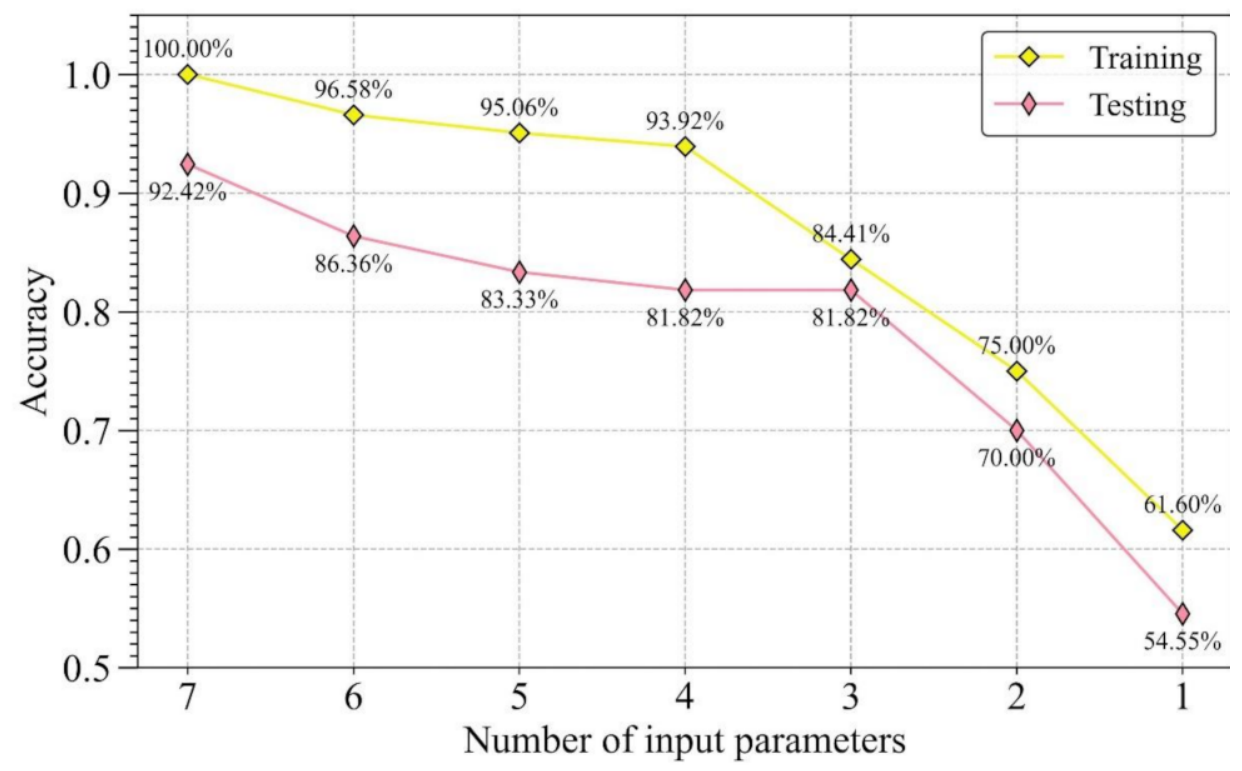

Figure 14. Model performance variation with the input parameters variation.

\subsection{Engineering Validation}

Xincheng Gold Mine and Sanshangao Gold Mine are located in Yantai, Shandong, China. Figure 15 presents their locations. After years of mining production, the two gold mines have become mines with a mining depth of more than $1000 \mathrm{~m}$ in China. To meet production needs, it is necessary to excavate ores in deeper strata. Due to the complexity of deep high stress and geological conditions, many engineering problems are inevitably faced in deep mining operations, among which rockburst poses a severe threat to the safety of facilities and workers. A series of field investigations and rock mechanics tests were carried out in the two gold mines to avoid the threat of rockburst to shaft construction. Seven rock blocks were taken in different locations in the Xincheng Gold Mine, and five rock blocks were taken in the Sanshandao Gold Mine. These rock blocks were processed into standard specimens for rock mechanics tests and in-situ stress analysis [63]. Table 15 presents the rock parameters used to foretell rockburst. According to the standard of classification for intensities of rockburst in Table 3, the rockburst level of each site was determined. The DF model was used to evaluate the rockburst, and Table 15 shows the predicted results. The predicted results of the DF model are consistent with the actual rockburst situation. These results suggest that the DF model has superior engineering practicability.

Table 15. Application of DF model in practical engineering.

\begin{tabular}{|c|c|c|c|c|c|c|c|c|c|c|}
\hline No. & Engineering & $\sigma_{\theta} / \mathrm{MPa}$ & $\sigma_{c} / \mathrm{MPa}$ & $\sigma_{t} / \mathrm{MPa}$ & $S C F$ & $B_{1}$ & $B_{2}$ & $W_{e t}$ & Actual Grade & Predicted Grade \\
\hline 1 & Xincheng & 87.60 & 139.07 & 10.63 & 0.63 & 13.08 & 0.86 & 5.56 & $S$ & $S$ \\
\hline 2 & Gold Mine & 108.31 & 149.99 & 11.97 & 0.72 & 12.53 & 0.85 & 6.88 & $S$ & $S$ \\
\hline 3 & & 89.46 & 155.45 & 12.05 & 0.58 & 12.90 & 0.86 & 3.98 & $S$ & S \\
\hline 4 & & 100.00 & 137.52 & 13.73 & 0.73 & 10.01 & 0.82 & 5.27 & $S$ & $S$ \\
\hline 5 & & 107.25 & 182.67 & 12.11 & 0.59 & 15.08 & 0.88 & 5.48 & $S$ & $S$ \\
\hline 6 & & 107.87 & 140.38 & 12.06 & 0.77 & 11.64 & 0.84 & 8.50 & $S$ & $S$ \\
\hline 7 & & 109.57 & 174.34 & 12.07 & 0.63 & 14.44 & 0.87 & 7.69 & $S$ & $S$ \\
\hline 8 & Sanshandao & 94.64 & 160.94 & 9.74 & 0.59 & 16.52 & 0.89 & 4.94 & $M$ & $M$ \\
\hline 9 & Gold Mine & 32.45 & 138.25 & 9.04 & 0.23 & 15.29 & 0.88 & 3.73 & $\mathrm{~L}$ & $\mathrm{~L}$ \\
\hline 10 & & 23.13 & 146.29 & 19.6 & 0.16 & 7.46 & 0.76 & 6.45 & $\mathrm{~N}$ & $\mathrm{~N}$ \\
\hline 11 & & 34.12 & 154.28 & 13.98 & 0.22 & 11.04 & 0.83 & 4.61 & $\mathrm{~L}$ & $\mathrm{~L}$ \\
\hline 12 & & 34.07 & 128.5 & 11.71 & 0.27 & 10.97 & 0.83 & 1.92 & $\mathrm{~N}$ & $\mathrm{~N}$ \\
\hline
\end{tabular}




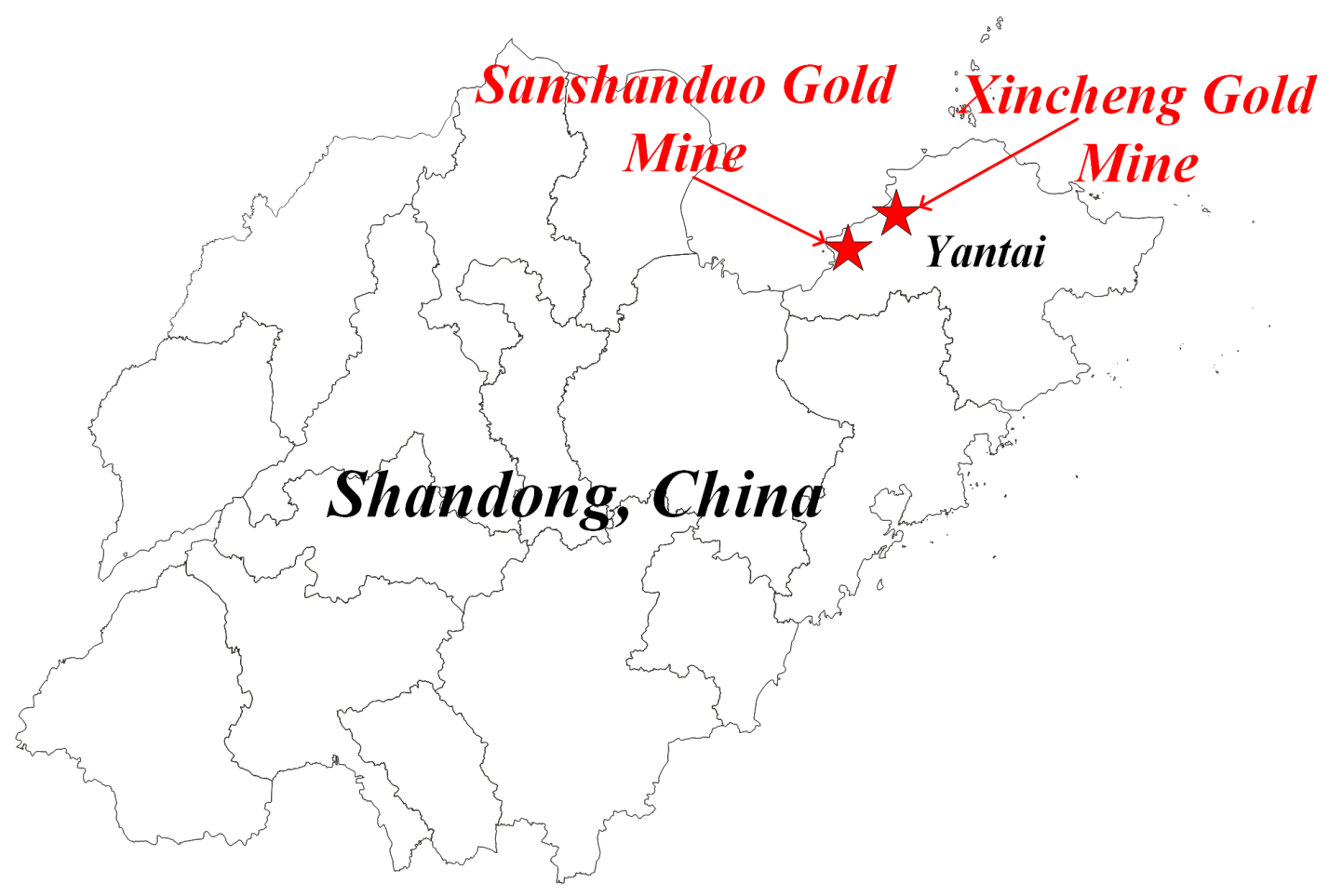

Figure 15. The location of Xincheng Gold Mine and Sanshandao Gold Mine.

\section{Limitations and Future Studies}

Rockburst is a complex geological disaster that is related to many factors, such as geological structure, in-situ stress conditions, rock strength, excavation method, excavation size, etc. However, in this study, only seven related parameters were considered to build the intelligent model for rockburst prediction. Other parameters, such as rock quality index, rock integrity coefficient, and the geometric size of the cross-section of the excavation, are also essential to determine rockburst level. In the future, more influential factors should be considered to add to the database. Additionally, increasing the size of the database contributes to building a more powerful intelligent rockburst prediction model. As for the DF model, to apply DF to predict rockburst in different engineering problems, it is necessary to tune the hyperparameters of DF according to the size and complexity of data.

\section{Conclusions}

(1) Deep forest, a novel tree-based ensemble model, was proposed to build the rockburst prediction model based on 329 collected real rockburst cases. Bayesian optimization was used to turn the hyperparameters of the DF. The DF had $100 \%$ accuracy in the training set and $92.4 \%$ accuracy in the testing set, and it performed better than other ML models and can forecast massive rockburst disasters.

(2) $\sigma_{\theta}$ and $W_{e t}$ are the essential parameters that affect the performance of the DF model for rockburst prediction. Sensitivity analysis reveals that more factors can be taken into account to build a more accurate rockburst prediction model for the complexity of rockburst. Moreover, it also confirms that the proposed DF model has good performance with fewer input parameters.

(3) A field investigation was carried out in the Xincheng Gold Mine and Sanshandao Gold mine, Shandong, China, and the collected rock blocks were tested in the laboratory. The obtained parameters were input into the trained DF model, and the predicted results matched the rockburst situation on site. The validation datasets from gold mines can expand the rockburst database to establish more powerful models.

(4) The DF model is trained by the datasets from mines, tunnels, large underground chambers, traffic tunnels, etc., and it is validated by the cases from two gold mines. 
Accordingly, it is worth noting that the proposed DF model is not only applied to gold mines with a high level of accuracy but also is suitable for other deep mine and underground excavation engineering.

Supplementary Materials: The collected rockburst database can be found be downloaded at: https: / / www.mdpi.com/article/10.3390/math10050787/s1, Table S1: Collected rockburst database.

Author Contributions: Conceptualization, D.L. and Z.L.; methodology, Z.L.; software, Z.L.; validation, P.X.; investigation, P.X.; resources, D.L.; writing-original draft preparation, Z.L. and D.L.; writing-review and editing, D.L., D.J.A. and J.Z.; visualization, Z.L.; supervision, D.L.; project administration, D.L.; funding acquisition, D.L. All authors have read and agreed to the published version of the manuscript.

Funding: This research was supported by the National Natural Science Foundation of China (Grant No.:52074349).

Institutional Review Board Statement: Not applicable.

Informed Consent Statement: Not applicable.

Data Availability Statement: Not applicable.

Conflicts of Interest: The authors declare no conflict of interest.

\section{References}

1. Zhou, J.; Li, X.; Mitri, H.S. Evaluation method of rockburst: State-of-the-art literature review. Tunn. Undergr. Space Technol. 2018, 81, 632-659. [CrossRef]

2. Cai, M. Prediction and prevention of rockburst in metal mines-A case study of Sanshandao gold mine. J. Rock Mech. Geotech. Eng. 2016, 8, 204-211. [CrossRef]

3. Afraei, S.; Shahriar, K.; Madani, S.H. Developing intelligent classification models for rock burst prediction after recognizing significant predictor variables, Section 1: Literature review and data preprocessing procedure. Tunn. Undergr. Space Technol. 2019, 83, 324-353. [CrossRef]

4. Xue, Y.; Bai, C.; Kong, F.; Qiu, D.; Li, L.; Su, M.; Zhao, Y. A two-step comprehensive evaluation model for rockburst prediction based on multiple empirical criteria. Eng. Geol. 2020, 268, 105515. [CrossRef]

5. Zhai, S.; Su, G.; Yin, S.; Zhao, B.; Yan, L. Rockburst characteristics of several hard brittle rocks: A true triaxial experimental study. J. Rock Mech. Geotech. Eng. 2020, 12, 279-296. [CrossRef]

6. Khan, N.M.; Ahmad, M.; Cao, K.; Ali, I.; Liu, W.; Rehman, H.; Hussain, S.; Rehman, F.U.; Ahmed, T. Developing a new bursting liability index based on energy evolution for coal under different loading rates. Sustainability 2022, 14, 1572. [CrossRef]

7. Wang, S.; Li, X.; Yao, J.; Gong, F.; Li, X.; Du, K.; Tao, M.; Huang, L.; Du, S. Experimental investigation of rock breakage by a conical pick and its application to non-explosive mechanized mining in deep hard rock. Int. J. Rock Mech. Min. Sci. 2019, $122,104063$. [CrossRef]

8. Wang, S.; Sun, L.; Li, X.; Wang, S.; Du, K.; Li, X.; Feng, F. Experimental investigation of cuttability improvement for hard rock fragmentation using conical cutter. Int. J. Geomech. 2021, 21, 06020039. [CrossRef]

9. Wang, J.; Apel, D.B.; Pu, Y.; Hall, R.; Wei, C.; Sepehri, M. Numerical modeling for rockbursts: A state-of-the-art review. J. Rock Mech. Geotech. Eng. 2021, 13, 457-478. [CrossRef]

10. Pu, Y.; Apel, D.B.; Liu, V.; Mitri, H. Machine learning methods for rockburst prediction-state-of-the-art review. Int. J. Min. Sci. Technol. 2019, 29, 565-570. [CrossRef]

11. Ma, L.; Khan, N.M.; Cao, K.; Rehman, H.; Salman, S.; Rehman, F.U. Prediction of sandstone dilatancy point in different water contents using infrared radiation characteristic: Experimental and machine learning approaches. Lithosphere 2022, 2021, 3243070. [CrossRef]

12. Khan, N.M.; Ma, L.; Cao, K.; Hussain, S.; Liu, W.; Xu, Y.; Yuan, Q.; Gu, J. Prediction of an early failure point using infrared radiation characteristics and energy evolution for sandstone with different water contents. Bull. Eng. Geol. Environ. 2021, 80, 6913-6936. [CrossRef]

13. Zhou, J.; Li, X.; Mitri, H.S. Classification of rockburst in underground projects: Comparison of ten supervised learning methods. J. Comput. Civ. Eng. 2016, 30, 04016003. [CrossRef]

14. Li, N.; Jimenez, R. A logistic regression classifier for long-term probabilistic prediction of rock burst hazard. Nat. Hazards 2018, 90, 197-215. [CrossRef]

15. Ghasemi, E.; Gholizadeh, H.; Adoko, A.C. Evaluation of rockburst occurrence and intensity in underground structures using decision tree approach. Eng. Comput. 2020, 36, 213-225. [CrossRef]

16. Pu, Y.; Apel, D.B.; Lingga, B. Rockburst prediction in kimberlite using decision tree with incomplete data. J. Sustain. Min. 2018, 17, 158-165. [CrossRef] 
17. Li, N.; Feng, X.; Jimenez, R. Predicting rock burst hazard with incomplete data using Bayesian networks. Tunn. Undergr. Space Technol. 2017, 61, 61-70. [CrossRef]

18. Zhou, J.; Guo, H.; Koopialipoor, M.; Jahed Armaghani, D.; Tahir, M. Investigating the effective parameters on the risk levels of rockburst phenomena by developing a hybrid heuristic algorithm. Eng. Comput. 2021, 37, 1679-1694. [CrossRef]

19. Zhou, J.; Koopialipoor, M.; Li, E.; Armaghani, D.J. Prediction of rockburst risk in underground projects developing a neuro-bee intelligent system. Bull. Eng. Geol. Environ. 2020, 79, 4265-4279. [CrossRef]

20. Li, D.; Liu, Z.; Xiao, P.; Zhou, J.; Jahed Armaghani, D. Intelligent rockburst prediction model with sample category balance using feedforward neural network and Bayesian optimization. Undergr. Space 2022, in press. [CrossRef]

21. Pu, Y.; Apel, D.B.; Wang, C.; Wilson, B. Evaluation of burst liability in kimberlite using support vector machine. Acta Geophys. 2018, 66, 973-982. [CrossRef]

22. Lin, Y.; Zhou, K.; Li, J. Application of Cloud Model in Rock Burst Prediction and Performance Comparison with Three Machine Learning Algorithms. IEEE Access 2018, 6, 30958-30968. [CrossRef]

23. Wang, S.-M.; Zhou, J.; Li, C.-Q.; Armaghani, D.J.; Li, X.-B.; Mitri, H.S. Rockburst prediction in hard rock mines developing bagging and boosting tree-based ensemble techniques. J. Cent. South Univ. 2021, 28, 527-542. [CrossRef]

24. Xie, X.; Jiang, W.; Guo, J. Research on rockburst prediction classification based on GA-XGB model. IEEE Access 2021, 6, 83993-84020. [CrossRef]

25. Zhang, J.; Wang, Y.; Sun, Y.; Li, G. Strength of ensemble learning in multiclass classification of rockburst intensity. Int. J. Numer. Anal. Methods Geomech. 2020, 44, 1833-1853. [CrossRef]

26. Liang, W.; Sari, A.; Zhao, G.; McKinnon, S.D.; Wu, H. Short-term rockburst risk prediction using ensemble learning methods. Nat. Hazards 2020, 104, 1923-1946. [CrossRef]

27. Liang, W.; Sari, Y.A.; Zhao, G.; McKinnon, S.D.; Wu, H. Probability estimates of short-term rockburst risk with ensemble classifiers. Rock Mech. Rock Eng. 2021, 54, 1799-1814. [CrossRef]

28. Yin, X.; Liu, Q.; Pan, Y.; Huang, X.; Wu, J.; Wang, X. Strength of stacking technique of ensemble learning in rockburst prediction with imbalanced data: Comparison of eight single and ensemble models. Nat. Resour. Res. 2021, 30, 1795-1815. [CrossRef]

29. Li, D.; Liu, Z.; Armaghani, D.J.; Xiao, P.; Zhou, J. Novel ensemble intelligence methodologies for rockburst assessment in complex and variable environments. Sci. Rep. 2022, 12, 1844. [CrossRef]

30. Zhou, Z.-H.; Feng, J. Deep forest. arXiv 2017, arXiv:1702.08835. [CrossRef]

31. Zhou, J.; Qiu, Y.; Zhu, S.; Armaghani, D.J.; Khandelwal, M.; Mohamad, E.T. Estimation of the TBM advance rate under hard rock conditions using XGBoost and Bayesian optimization. Undergr. Space 2021, 6, 506-515. [CrossRef]

32. Zhou, J.; Asteris, P.G.; Armaghani, D.J.; Pham, B.T. Prediction of ground vibration induced by blasting operations through the use of the Bayesian Network and random forest models. Soil Dyn. Earthq. Eng. 2020, 139, 106390. [CrossRef]

33. Han, H.; Armaghani, D.J.; Tarinejad, R.; Zhou, J.; Tahir, M. Random forest and bayesian network techniques for probabilistic prediction of flyrock induced by blasting in quarry sites. Nat. Resour. Res. 2020, 29, 655-667. [CrossRef]

34. Shahriari, B.; Swersky, K.; Wang, Z.; Adams, R.P.; Freitas, N.D. Taking the human out of the loop: A review of bayesian optimization. Proc. IEEE 2015, 104, 148-175. [CrossRef]

35. Liang, X. Image-based post-disaster inspection of reinforced concrete bridge systems using deep learning with Bayesian optimization. Comput.-Aided Civ. Infrastruct. Eng. 2019, 34, 415-430. [CrossRef]

36. Zhang, Q.; Hu, W.; Liu, Z.; Tan, J. TBM performance prediction with Bayesian optimization and automated machine learning. Tunn. Undergr. Space Technol. 2020, 103, 103493. [CrossRef]

37. Sameen, M.I.; Pradhan, B.; Lee, S. Application of convolutional neural networks featuring Bayesian optimization for landslide susceptibility assessment. Catena 2020, 186, 104249. [CrossRef]

38. Lu, X.; Duan, Z.; Qian, Y.; Zhou, W. A malicious code classification method based on deep forest. J. Softw. 2020, 31, 1454-1464.

39. Breiman, L. Random Forests. MLear 2001, 45, 5-32.

40. Snoek, J.; Larochelle, H.; Adams, R.P. Practical bayesian optimization of machine learning algorithms. In Proceedings of the Advances in Neural Information Processing Systems 25: 26th Annual Conference on Neural Information Processing Systems 2012, Lake Tahoe, NV, USA, 3-6 December 2012; Volume 25.

41. Yang, L.; Shami, A. On hyperparameter optimization of machine learning algorithms: Theory and practice. Neurocomputing 2020, 415, 295-316. [CrossRef]

42. Seeger, M. Gaussian processes for machine learning. Int. J. Neural Syst. 2008, 14, 69-106. [CrossRef] [PubMed]

43. Kushner, H.J. A new method of locating the maximum point of an arbitrary multipeak curve in the presence of noise. J. Basic Eng. 1964, 86, 97-106. [CrossRef]

44. Mockus, J.; Tiesis, V.; Zilinskas, A. The application of Bayesian methods for seeking the extremum. Towards Glob. Optim. 1978, 2, 2.

45. Jones, D.R.; Schonlau, M.; Welch, W.J. Efficient global optimization of expensive black-box functions. J. Glob. Optim. 1998, 13, 455-492. [CrossRef]

46. Brochu, E.; Hoffman, M.W.; De Freitas, N. Portfolio allocation for bayesian optimization. arXiv 2010, arXiv:1009.5419.

47. He, M.; Ren, F.; Liu, D. Rockburst mechanism research and its control. Int. J. Min. Sci. Technol. 2018, 28, 829-837. [CrossRef]

48. Zhou, J.; Li, X.; Shi, X. Long-term prediction model of rockburst in underground openings using heuristic algorithms and support vector machines. Saf. Sci. 2012, 50, 629-644. [CrossRef] 
49. Pu, Y.; Apel, D.B.; Xu, H. Rockburst prediction in kimberlite with unsupervised learning method and support vector classifier. Tunn. Undergr. Space Technol. 2019, 90, 12-18. [CrossRef]

50. Ran, L.; Ye, Y.; Hu, N.; Hu, C.; Wang, X. Classified prediction model of rockburst using rough sets-normal cloud. Neural Comput. Appl. 2019, 31, 8185-8193.

51. Xue, Y.; Li, Z.; Li, S.; Qiu, D.; Tao, Y.; Wang, L.; Yang, W.; Zhang, K. Prediction of rock burst in underground caverns based on rough set and extensible comprehensive evaluation. Bull. Eng. Geol. Environ. 2019, 78, 417-429. [CrossRef]

52. Wu, S.; Wu, Z.; Zhang, C. Rock burst prediction probability model based on case analysis. Tunn. Undergr. Space Technol. 2019, 93, 103069. [CrossRef]

53. Du, Z.; Xu, M.; Liu, Z.; Xuan, W. Laboratory integrated evaluation method for engineering wall rock rock-burst. Gold 2006, 27, 26-30.

54. Jia, Q.; Wu, L.; Li, B.; Chen, C.; Peng, Y. The comprehensive prediction model of rockburst tendency in tunnel based on optimized unascertained measure theory. Geotech. Geol. Eng. 2019, 37, 3399-3411. [CrossRef]

55. Xue, Y.; Bai, C.; Qiu, D.; Kong, F.; Li, Z. Predicting rockburst with database using particle swarm optimization and extreme learning machine. Tunn. Undergr. Space Technol. 2020, 98, 103287. [CrossRef]

56. Zhou, J.; Li, E.; Wang, M.; Chen, X.; Shi, X.; Jiang, L. Feasibility of stochastic gradient boosting approach for evaluating seismic liquefaction potential based on SPT and CPT case histories. J. Perform. Constr. Facil. 2019, 33, 04019024. [CrossRef]

57. Head, T.; MechCoder, G.L.; Shcherbatyi, I. Scikit-optimize/scikit-optimize: v0.5.2. Zenodo 2018, 1207017.

58. Taylor, K.E. Taylor Diagram Primer. Working Paper. 2005, pp. 1-4. Available online: http://www.atmos.albany.edu/daes/ atmclasses/atm401/spring_2016/ppts_pdfs/Taylor_diagram_primer.pdf (accessed on 8 February 2022).

59. Zhou, J.; Zhu, S.; Qiu, Y.; Armaghani, D.J.; Zhou, A.; Yong, W. Predicting tunnel squeezing using support vector machine optimized by whale optimization algorithm. Acta Geotech. 2022. [CrossRef]

60. Pedregosa, F.; Varoquaux, G.; Gramfort, A.; Michel, V.; Thirion, B.; Grisel, O.; Blondel, M.; Prettenhofer, P.; Weiss, R.; Dubourg, V. Scikit-learn: Machine learning in Python. J. Mach. Learn. Res. 2011, 12, 2825-2830.

61. Friedman, J.H. Greedy function approximation: A gradient boosting machine. Ann. Stat. 2001, 29, 1189-1232. [CrossRef]

62. Xiao, P.; Li, D.; Zhao, G.; Liu, H. New criterion for the spalling failure of deep rock engineering based on energy release. Int. J. Rock Mech. Min. Sci. 2021, 148, 104943. [CrossRef]

63. Xiao, P.; Li, D.; Zhao, G.; Liu, M. Experimental and Numerical Analysis of Mode I Fracture Process of Rock by Semi-Circular Bend Specimen. Mathematics 2021, 9, 1769. [CrossRef] 